Document downloaded from:

http://hdl.handle.net/10251/52668

This paper must be cited as:

Robles Martínez, A.; Ruano García, MV.; Ribes Bertomeu, J.; Seco Torrecillas, A.; Ferrer, J. (2014). Model-based automatic tuning of a filtration control system for submerged anaerobic membrane bioreactors (AnMBR). Journal of Membrane Science. 465:14-26. doi:10.1016/j.memsci.2014.04.012.

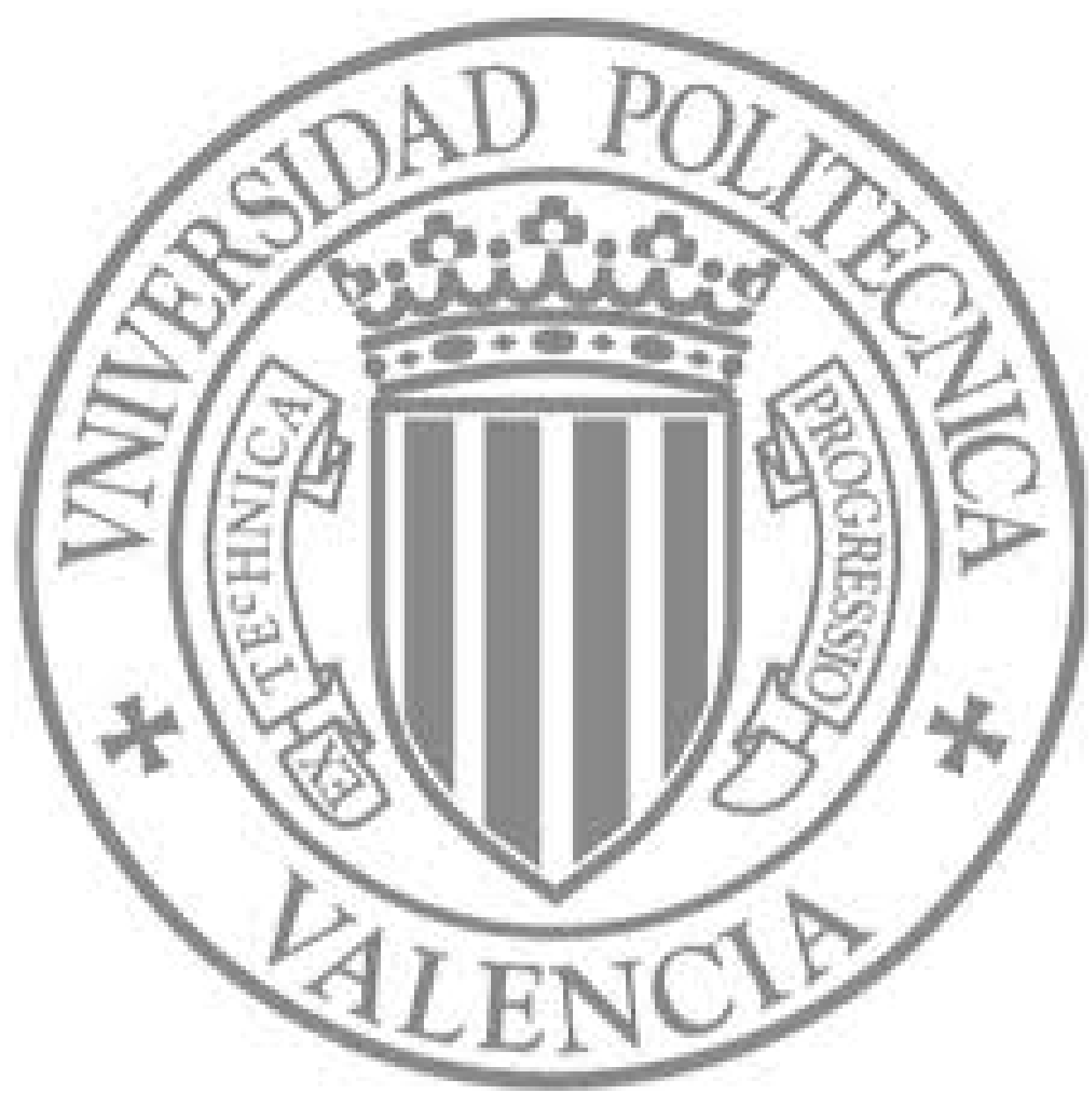

The final publication is available at

http://dx.doi.org/10.1016/j.memsci.2014.04.012

Copyright Elsevier 


\title{
Model-based automatic tuning of a filtration control system for submerged anaerobic membrane bioreactors (AnMBR)
}

\author{
A. Robles ${ }^{\mathrm{a}, *}$, M.V. Ruano ${ }^{\mathrm{a}, 1}$, J. Ribes $^{\mathrm{a}}$, A. Seco ${ }^{\mathrm{a}}$ and J. Ferrer ${ }^{\mathrm{b}}$ \\ a Departament d'Enginyeria Química, Escola Tècnica Superior d'Enginyeria, Universitat de \\ València, Avinguda de la Universitat s/n, 46100 Burjassot, Valencia, Spain (e-mail: \\ angel.robles@uv.es; mavictoria.ruano.garcia@fcc.es; josep.ribes@uv.es; aurora.seco@uv.es) \\ b Institut Universitari d'Investigació d'Enginyeria de l'Aigua i Medi Ambient, IIAMA, \\ Universitat Politècnica de València, Camí de Vera s/n, 46022 Valencia, Spain (e-mail: \\ jferrer@hma.upv.es) \\ * Corresponding author: tel. +34 9638799 61, fax +34 9638790 09, e-mail: \\ angel.robles@uv.es
}

\begin{abstract}
This paper describes a model-based method to optimise filtration in submerged AnMBRs. The method is applied to an advanced knowledge-based control system and considers three statistical methods: (1) sensitivity analysis (Morris screening method) to identify an input subset for the advanced controller; (2) Monte Carlo method (trajectory-based random sampling) to find suitable initial values for the control inputs; and (3) optimisation algorithm (performing as a supervisory controller) to re-calibrate these control inputs in order to minimise plant operating costs. The model-based supervisory controller proposed allowed filtration to be optimised with low computational demands (about 5 minutes). Energy savings of up to $25 \%$ were achieved when using gas sparging to scour membranes. Downtime for physical cleaning was about $2.4 \%$ of operating time. The operating cost of the AnMBR system after implementing the proposed supervisory controller was about $€ 0.045 / \mathrm{m}^{3}, 53.3 \%$ of which were energy costs.
\end{abstract}

\footnotetext{
${ }^{1}$ Present address: aqualia, gestión integral del agua, S.A., Avenida del Camino de Santiago, 40, 28050 Madrid, Spain
} 


\section{Keywords}

Industrial-scale membranes; model-based control; Monte Carlo procedure; Morris screening method; submerged anaerobic MBR (AnMBR)

\section{Highlights}

A model-based method to optimise filtration in AnMBRs is proposed.

It includes the Morris method, Monte Carlo procedure and an optimisation algorithm.

Energy savings during membrane scouring of up to $25 \%$ were achieved.

The supervisory controller resulted in AnMBR operating costs of about $€ 0.045 / \mathrm{m}^{3}$.

\section{Nomenclature}

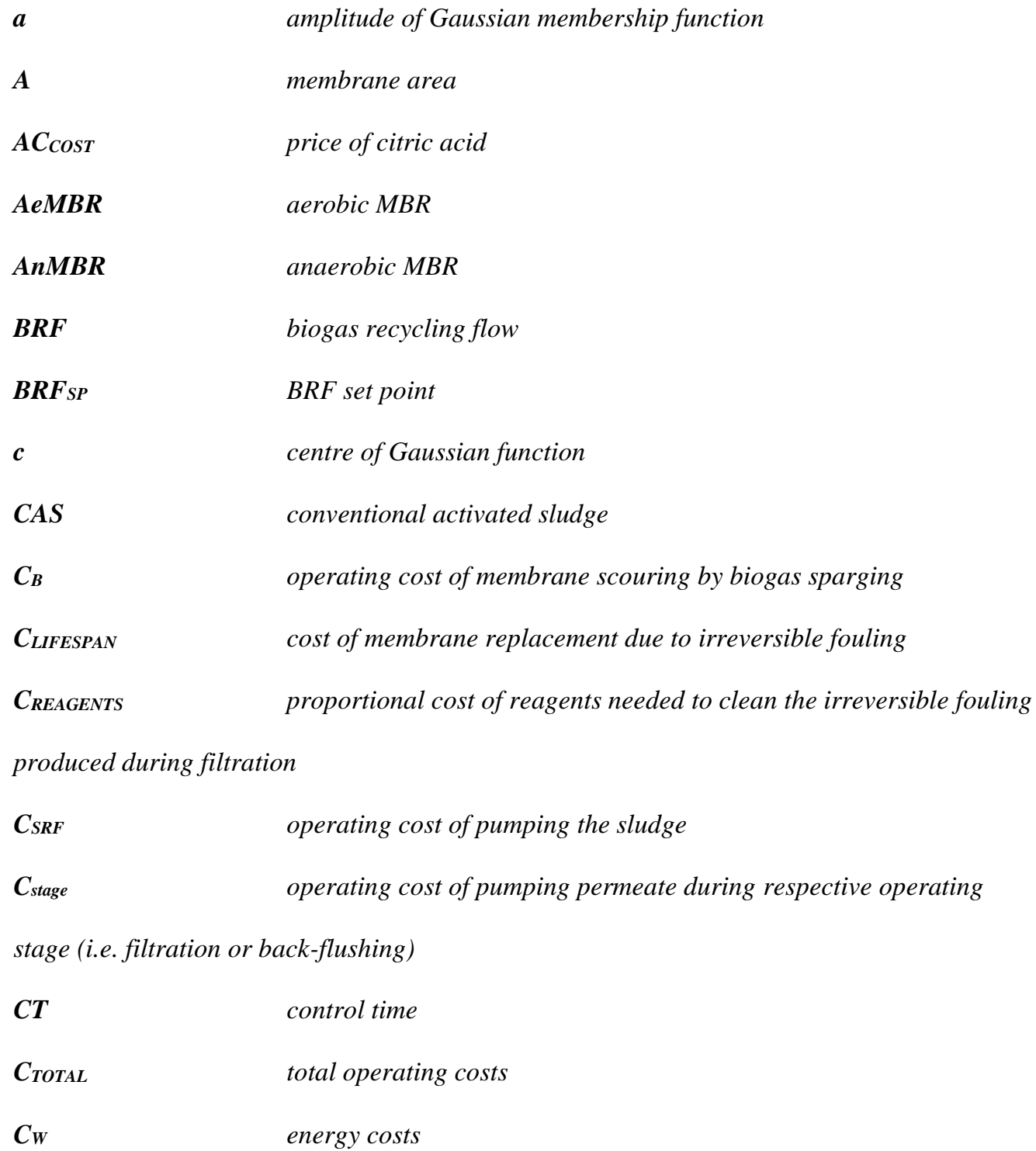




\begin{tabular}{|c|c|}
\hline$D$ & pipe diameter \\
\hline$E_{C O S T}$ & cost of energy \\
\hline$E E_{i}$ & elementary effect \\
\hline$f$ & friction factor \\
\hline$F_{i}$ & distribution of $S E E_{i}$ \\
\hline$F R_{C}$ & fouling rate related to cake-layer formation \\
\hline$F R_{C_{-} S P}$ & $F R_{C}$ set point \\
\hline$F R A E$ & $F R_{C}$ accumulated error \\
\hline$F R D E$ & $F R_{C}$ error difference \\
\hline$F R E$ & $F R_{C}$ error \\
\hline$|F R E|$ & absolute error of $F R_{C}$ \\
\hline$g$ & acceleration of gravity \\
\hline$G S A$ & global sensitivity analysis \\
\hline$H N$ & high negative \\
\hline$H P$ & high positive \\
\hline$I A E$ & integral absolute error \\
\hline$J_{20}$ & $20{ }^{\circ} \mathrm{C}$-normalised transmembrane flux \\
\hline$J_{T}$ & transmembrane flux at temperature $T$ \\
\hline$K_{20}$ & $20{ }^{\circ} \mathrm{C}$-normalised membrane permeability \\
\hline$\% K_{20}$ & maximum decrease in highest $K_{20}$ recorded during filtration \\
\hline$K_{20, M A X, F}$ & maximum $K_{20}$ during filtration \\
\hline$K_{20, M I N}$ & minimum $K_{20}$ \\
\hline$L$ & pipe length \\
\hline$L_{e q}$ & equivalent pipe length of accidental pressure drops \\
\hline$L N$ & low negative \\
\hline $\boldsymbol{L P}$ & low positive \\
\hline$M$ & molar flow rate of biogas \\
\hline$M B R$ & membrane bioreactor \\
\hline$M_{C O S T}$ & price per square metre of membrane area \\
\hline MIMO & multiple-input-multiple-output \\
\hline MLTS & mixed liquor total solids \\
\hline
\end{tabular}


$\operatorname{MLTS}_{M T}$

n

$N$

$\mathrm{NaClO}$

$\mathrm{NaClO} \operatorname{CosT}$

$N_{C, M A X}$

OT

$P_{1}$

$\boldsymbol{P}_{2}$

$p$

$\boldsymbol{P}$

$\boldsymbol{P F}_{\boldsymbol{r} i \rightarrow r j}$

$P F_{\text {max }}$

PID

$P_{k, i}$

$\boldsymbol{P}_{k, j}$

$q$

$q_{\text {stage }}$
MLTS in membrane tank

number of points considered when estimating $F R_{C}$

negative

sodium hypochlorite

price of $\mathrm{NaClO}$

maximum number of times the membrane can be cleaned

optimiser time

absolute inlet pressure

absolute outlet pressure

constant resolution

positive

position index

maximum value of $P F_{r i} \rightarrow r j$ for the number of input factors evaluated proportional-integrative-derivative

position of $k^{\text {th }}$ factor in ranking obtained by $r_{i}$

position of $k^{\text {th }}$ factor in ranking obtained by $r_{j}$

volumetric flow rate

volumetric flow rate during the corresponding operating stage (i.e.

filtration or back-flushing)

$\boldsymbol{r}$

$\boldsymbol{R}$

$\boldsymbol{R}_{C}$

$\boldsymbol{R}_{I}$

$\Delta \boldsymbol{R}_{\mathbf{I}, \text { filtration }}$

$\triangle \boldsymbol{R}_{I, M A X}$

cleaning starts

$\boldsymbol{R}_{M}$

$r_{\text {opt }}$

$\boldsymbol{R}_{T}$

s

$S E E_{i}$ number of times that elementary effect calculations are repeated gas constant for biogas

cake-layer resistance

irreversible layer resistance

increase in the irreversible fouling resistance during filtration

upper threshold of irreversible fouling resistance at which membrane

membrane resistance

optimal value for $r$

total membrane resistance

singleton value of singleton membership function

scaled elementary effect 


\begin{tabular}{|c|c|}
\hline$S E M_{i}$ & standard error of mean of factor $i$ \\
\hline SISO & single-input-single-output \\
\hline$S R F$ & sludge recycling flow \\
\hline$S R F_{S P}$ & SRF set point \\
\hline$S T$ & sample time \\
\hline$T$ & temperature \\
\hline$T_{\text {gas }}$ & biogas temperature \\
\hline$T M P$ & transmembrane pressure \\
\hline $\operatorname{TMP}(t)$ & TMP at sample time \\
\hline$T M P_{C}$ & TMP through the cake-layer \\
\hline$T M P_{M A X}$ & maximum $T M P$ \\
\hline TMP $P_{\text {stage }}$ & TMP during the corresponding operating stage (i.e. filtration or \\
\hline \multicolumn{2}{|c|}{ back-flushing) } \\
\hline $\boldsymbol{V}$ & fluid velocity \\
\hline$V B R F$ & variation in the biogas recycling flow \\
\hline$V_{T}$ & net volume of treated wastewater \\
\hline$W_{B}$ & blower energy consumption \\
\hline Wback-flushing & back-flushing energy consumption \\
\hline$W_{\text {filtration }}$ & filtration energy consumption \\
\hline$W_{S R F}$ & sludge recycling flow energy consumption \\
\hline$W_{\text {TOTAL }}$ & total energy consumption \\
\hline WWTP & wastewater treatment plant \\
\hline$X_{A C}$ & amount of citric acid required for membrane cleaning \\
\hline$X_{m_{C}}$ & dry mass of cake on the membrane surface \\
\hline$X_{m_{I}}$ & dry mass of irreversible fouling on the membrane surface \\
\hline $\boldsymbol{X}_{\mathrm{NaClO}}$ & amount of $\mathrm{NaClO}$ required for membrane cleaning \\
\hline$X_{T S}$ & TS concentration in the mixed liquor \\
\hline$Z$ & zero \\
\hline$Z_{1}-Z_{2}$ & difference in height \\
\hline $\boldsymbol{\kappa}$ & compression index \\
\hline
\end{tabular}




\begin{tabular}{|c|c|}
\hline$\alpha_{C}$ & average specific cake resistance at time $t$ \\
\hline$\alpha_{C}(t)$ & $\alpha_{C}$ at time $t$ \\
\hline$\alpha_{I}$ & average specific irreversible fouling resistance \\
\hline クblower & overall mechanical and electrical efficiency of the blower \\
\hline$\eta_{p u m p}$ & overall mechanical and electrical efficiency of the pump \\
\hline$\mu_{20}$ & permeate dynamic viscosity at $20^{\circ} \mathrm{C}$ \\
\hline$\mu$ & mean \\
\hline$\mu^{*}$ & absolute mean \\
\hline$\mu_{P_{k, i}, P_{k, j}}$ & average position of $k^{\text {th }}$ factor in ranking obtained by $r_{i}$ and $r_{j}$ \\
\hline$\rho_{\text {sludge }}$ & sludge density \\
\hline$\sigma$ & standard deviation \\
\hline$\sigma_{i}$ & standard deviation of factor $i$ \\
\hline$\omega_{C}(t)$ & mass of cake deposited per membrane area at time $t$ \\
\hline$\omega_{I}$ & mass of irreversible fouling per membrane area \\
\hline
\end{tabular}

\section{Introduction}

Mathematical modelling is a powerful tool for studying complex systems such as AnMBRs [1] and may help provide an insight into the factors that play a key role in membrane fouling [2]. Indeed, certain models have been found to be useful for different objectives related to WWTPs, such as the development of operation and control strategies designed to optimise process performance [3, 4, 5]. Different optimisation studies have been carried out to determine the best operating conditions in WWTPs. The aim of these studies is mainly to minimise operating costs whilst maximising effluent quality by evaluating control strategies (see, for instance, $[6,7,8,9]$ ) and/or optimising the set points of control systems (see, for instance, $[10,11,12])$. 
Hence, the mathematical modelling of filtration in AnMBRs may be very useful for the design, prediction and control of membrane technology applied to wastewater treatment [13].

The main challenge of AnMBR technology is to control membrane fouling whilst optimising energy consumption but few scientific papers and innovations aimed at minimising operating costs and enhancing AnMBR efficiency have been published or patented [14]. Diverse authors have recently applied different optimisation methods to AeMBRs. Mannina and Cosenza [15] for example, used Monte Carlo simulations to analyse five different AeMBR operating scenarios by applying an integrated MBR model proposed in previous studies $[16,17]$. The main aim of Mannina and Cosenza [15] was to compare and discuss their findings about the energy requirements, effluent quality and economic costs of the scenarios analysed. Maere et al. [18] developed an adhoc platform (BSM-MBR) based on the COST/Benchmark Simulation Model No.1 (BSM1) [19]. This platform was used to evaluate different AeMBR control strategies by quantifying energy requirements in terms of aeration, pumping and mixing. Gabarrón et al. [20] evaluated several energy-saving strategies of seven stand-alone, hybrid and dual-stream, full-scale AeMBRs. These optimisation strategies were shown to reduce energy needs and membrane fouling. However, only a few studies have been published about the optimisation of AnMBR systems.

As regards the model-based control of filtration in AeMBR technology, Drews et al. [21, 22] developed a control system designed to improve filtration efficiency by applying mathematical models enabling appropriate actions to increase permeability over time. On the other hand, Busch et al. [23] proposed a model-based run-to-run control system that optimised the adjusted variables (filtration and back-flushing stages) 
after each filtration cycle. However, further research is needed into model-based control strategies for filtration in AnMBR technology due to the limited knowledge about fouling in systems of this type. As regards knowledge-based control of filtration in AeMBR technology, Huyskens et al. [24] validated an advanced control system that evaluated the reversible fouling propensity by using a specific on-line fouling measuring tool [25]; Ferrero et al. [26, 27, 28] developed a controller to supervise filtration and achieved considerable energy savings (up to 21\%) in membrane scouring; and Soleimani et al. [29] optimised membrane operation by combining neural networks and genetic algorithms.

As regards the knowledge-based control of filtration in AnMBR technology, in a previous paper we presented a knowledge-based advanced control system (including a fuzzy-logic controller) that reduced both the energy requirements of membrane scouring and the downtime needed for back-flushing [30]. To minimise long-term operating costs, the set points of this knowledge-based advanced control system should be modified over time to taken into account the dynamic operating conditions typically observed in WWTPs. Furthermore, it is well known that the automatic recalibration of control inputs is advisable when operating conditions are variable [31]. Therefore, advanced controller optimisation involves adjusting not only the set points, but also the different control parameters included in the fuzzy-logic controller (i.e. $C T, S T$, centre and amplitude of each input fuzzy set, and singleton value of each output fuzzy set).

Fuzzy-logic controllers applied to wastewater treatment usually contain large numbers of control parameters - making it difficult to calibrate them. Therefore, before fine-tuning these controllers, regardless of the optimisation method applied, it is necessary to select the most important parameters to be adjusted in each particular 
application. This is when the main challenge arises, i.e. how is an identifiable input subset to be selected from amongst the many control parameters.

Sensitivity analysis provides useful information for modellers because it attempts to quantify how changes to a model's input factors affect its outputs. Hence, sensitivity analysis is an attempt to determine the most influential (identifiable) factors of a model, i.e. those with the greatest impact on the outputs of a model. Sensitivity analysis can also be used to identify the most important input factors in advanced control systems such as those based on fuzzy logic. For instance, different applications of the Morris screening method [32] in determining the most influential input factors in fuzzy-logic controllers can be found in the literature $[33 ; 34]$. Furthermore, this sensitivity analysis has been incorporated into a control system calibration method in order to find a subset of input factors suitable for fine-tuning fuzzy-logic controllers [35].

In this study, we propose a model-based supervisory controller which is to be applied to the above-mentioned knowledge-based advanced control system [30] in order to optimise filtration in submerged AnMBRs. This supervisory system uses a resistancein-series-based filtration model developed for AnMBR technology [36] in order to find the optimum combination of set points for the advanced controller resulting in minimum operating costs (evaluated by a specific objective function). In addition, the optimum combination of fuzzy-logic control parameters resulting in the minimum IAE over time was also obtained for each change in the advanced controller set points.

The optimisation method proposed in this study is based on model simulations and considers three statistical methods: (1) sensitivity analysis (Morris screening method) to find an identifiable input subset for the control system; (2) Monte Carlo procedure 
(using trajectory-based random sampling technique) to find adequate initial conditions; and (3) optimisation algorithm (performing as supervisory controller) to obtain the optimum input value combination that minimises both $I A E$ and operating costs. The first two approaches (Morris and Monte Carlo procedures) are only applied once at the outset when considering a wide range of the system's operating conditions. Both approaches permit automatic on-line tuning with low computational cost because they provide the subset of factors to be evaluated over time and a suitable starting point (i.e. local optimum) for the optimisation algorithm.

\section{Materials and methods}

As mentioned earlier, in this study we propose a model-based supervisory controller for filtration in AnMBR systems. This supervisory controller was applied to an advanced fuzzy-logic control system for filtration in AnMBRs [30]. It uses a resistance-in-series-based filtration model developed in AnMBRs [36] to select the optimum set points for the advanced controller that minimise operating costs. To obtain representative results that could be extrapolated to full-scale plants, both the advanced control system and the filtration model were validated beforehand in an AnMBR system fitted with industrial-scale hollow-fibre membranes and fed with urban wastewater from the pre-treatment of the Carraixet WWTP (Valencia, Spain) [30, 36].

\subsection{AnMBR plant description and monitoring}

The AnMBR consists of an anaerobic reactor with a total volume of $1.3 \mathrm{~m}^{3}$ connected to two membrane tanks each with a total volume of $0.8 \mathrm{~m}^{3}$. Each membrane 
tank includes one submerged hollow-fibre membrane commercial system (PURON ${ }^{\circledR}$, Koch Membrane Systems, $0.05 \mu \mathrm{m}$ pore size, $30 \mathrm{~m}^{2}$ total filtering area, and outside-in filtration). Further details on this AnMBR system can be found in Robles et al. [37].

In addition to being monitored on line, grab samples of anaerobic sludge were taken once a day to assess filtration performance. MLTS concentration was determined according to Standard Methods [38] using procedure $2540 \mathrm{~B}$.

\subsection{Advanced control system description}

The advanced control system [30] used in this study aims to minimise operating costs in AnMBR technology by modifying not only the gas sparging intensity used in membrane scouring but also the back-flushing frequency. The advanced controller consists of a MIMO control structure including a number of lower-layer controllers and one upper-layer controller. The lower-layer controllers are based on classic on-off and feedback PID (proportional-integral-derivative) controllers consisting of SISO control structures. The upper-layer controller is based on knowledge-based theory and consists of a MIMO control structure including fuzzy-logic control and knowledge-based rules. The upper-layer controller allows the different set points of the controlled variables in the lower-layer controllers to be established according to the data gathered from the different sensors installed in the plant.

The inputs of this advanced controller include, besides the fuzzy-logic control parameters, the following: $F R_{C_{-} S P}, T M P_{M A X}, \% K_{20}$ and $S R F_{S P}$.

\subsubsection{Lower-layer controllers}


The lower-layer controllers in the advanced control system are: three PID controllers to adjust the rotating speed of the sludge recycling pump, the permeate pump and the biogas recycling blower using the respective frequency converter in order to keep each flow close to the respective set point; and one on-off controller that determines the membrane operating stage by changing both the position of the respective on-off valves and the flux direction of the permeate pump. The PID controllers were tuned by trial and error, resulting in good performance under different situations.

\subsubsection{Upper-layer control structure}

The upper-layer controller can be divided into two subsections: (i) a preliminary group of knowledge-based rules, where the membrane operating stage is established (filtration or back-flushing); and (ii) fuzzy-logic control, where $F R_{C}$ is controlled by adjusting $B R F_{S P \text {. }}$

\subsubsection{Control variables}

$J_{20}$ was defined as shown in Eq. 1 in order to reflect the dependence of permeate viscosity on $\mathrm{T}$.

$$
J_{20}=J_{T} \cdot \exp (-0.0239(T-20))
$$

The resistance-in-series model considered in this study is shown in Eq. 2. In this classic filtration model, $R_{T}$ was represented by $R_{M}, R_{I}$ and $R_{C}$. 


$$
K_{20}=\frac{1}{\mu_{20} \cdot R_{T}}=\frac{1}{\mu_{20} \cdot\left(R_{M}+R_{I}+R_{C}\right)}=\frac{J_{20}}{T M P}
$$

In this study, $F R_{C}$ at time $t$ was calculated using a classical regression model as follows:

$$
F R_{C}(t)=\frac{\partial T M P_{C}}{\partial t}=\frac{n \cdot \sum_{1}^{n}\left(T M P_{C, i} \cdot t_{i}\right)+\sum_{1}^{n} T M P_{C, i} \cdot \sum_{1}^{n} t_{i}}{n \cdot \sum_{1}^{n} T M P_{C, i}{ }^{2}-\left(\sum_{1}^{n} T M P_{C, i}\right)^{2}}
$$

In this study, the number of points considered for estimating $F R_{C}$ (i.e. $n$ ) was set to 5.

The evolution of $T M P_{C}$ over time was expressed as follows:

$$
T M P_{C}(t)=J_{20}(t) \cdot \mu_{20} \cdot R_{C}(t)=J_{20}(t) \cdot \mu_{20} \cdot \alpha_{C}(t) \cdot \omega_{C}(t)
$$

The sampling time was set to one fifth of the control time, i.e. $S T=C T / 5$.

\subsubsection{Preliminary knowledge-based rules}

Two different knowledge-based rules for back-flushing initiation were defined in the advanced control system: (1) when $K_{20}$ is below $K_{20, M I N}$, i.e. a function of $K_{20, M A X}$ (see Eq. 5); and (2) when $T M P_{M A X}$ is reached.

$$
K_{20, M I N}=\% K_{20} \cdot K_{20, M A X}
$$




\subsubsection{Fuzzy-logic controller description}

The fuzzy-logic controller is only active during filtration since the aim is to control $F R_{C}$. The output variable of the fuzzy-logic controller is $V B R F$. The controller determines $V B R F$ on the basis of three inputs obtained from the estimated $F R_{C}$, i.e. FRE, FRAE and FRDE. Three Gaussian membership functions were considered for each input of the fuzzy-logic controller: $N, Z$ and $P$. Therefore, 9 Gaussian membership functions were defined in the fuzzification stage. As each Gaussian membership function is defined by two inputs (centre, $c$, and amplitude, $a$ ), the fuzzy-logic controller has a total of 18 inputs corresponding to the fuzzification stage. Four singleton membership functions were defined as output linguistic variables in the defuzzification stage: $H N, L N, L P$ and $H P$. In this case, each singleton membership function is defined by just one input ( $s$, singleton value). Therefore, the fuzzy-logic controller has a total of 4 inputs for the defuzzification stage. Including $C T$, a total of 23 inputs must be adjusted in the fuzzy-logic controller (as mentioned before, $S T$ was set to $C T / 5$ in this study). Hence, it is essential to reduce the number of tuning parameters.

When classifying the parameters of the fuzzy-logic controller, acronyms for each parameter were constructed as follows: "abbreviation of input/output variable of the controller" + “c/a/s" (centre/amplitude/singleton) + "input/output membership function abbreviation in the fuzzification/defuzzification stage". For instance, FREaN is the acronym of the amplitude of the Negative Gaussian membership function for the error of $F R_{C}$; and $V B R F s H P$ is the acronym of the singleton value of the High Positive singleton membership function for the variation in $B R F_{S P}$. 


\subsection{Model-based optimisation method}

Figure 1 is a schematic representation of the model-based optimisation method proposed in our study. As Figure 1a shows, Morris simulations are conducted (Step A) in order to select the highly-influential control inputs (Step B) from the knowledgebased advanced control system (including both set points and fuzzy-logic control parameters). The highly-influential input factors chosen were the input factors that have linear and additive effects on the output, which is desirable for on-line parameter estimation (e.g. automatic tuning). It is essential to screen the other factors (both influential and otherwise) in order to reduce the computational cost of the model-based supervisory controller. Once the highly-influential input subset is selected, a Monte Carlo procedure (using trajectory-based random sampling technique) is conducted (Step C) to establish adequate initial values (Step D) for the advanced control system. Then the inputs of the advanced controller are updated (Step E). The model-based supervisory controller is initiated (Step F) for each $O T$ in order to optimise plant performance by updating the optimal inputs of the advanced control system (Step G).

Figure $1 \mathrm{~b}$ is a schematic representation of the model-based supervisory controller. As this figure shows, the real-time optimiser adjusts the advanced controller set points periodically (Step H) and calculates an objective function (Step I) by applying the above-mentioned filtration model (Step J). On the other hand, the fuzzy-logic controller was previously tuned by trial and error based on our technical knowledge of process and controller performance. Therefore, as Figure 1b shows, the model-based supervisory controller also adjusts the highly-influential fuzzy-logic control parameters (Step K) and calculates another objective function (Step L) by applying a filtration model (Step M). In order to minimise the control error, the fuzzy-logic control parameters must be 
calibrated for each combination of set points.

The Morris screening method and the Monte Carlo procedure are applied only once because the system's entire range of operating conditions is considered in the first step. These approaches provide a suitable starting point for the supervisory controller (i.e. local optimum) and a simplified number of factors to be explored when applying the subsequent optimisation algorithm (thus reducing the computational cost of the realtime optimiser). Therefore, the model-based automatic tuning method we propose provides adequate and feasible optimisation for systems with a great many parameters such as the one in this study.

\subsubsection{Model description}

The filtration model used in this study [36] gives the dynamic evolution of TMP by applying Eq. 6 and Eq. 7.

$$
\begin{aligned}
& \operatorname{TMP}(t)=J \cdot \mu \cdot R_{T} \\
& R_{T}=R_{M}+R_{C}+R_{I}=R_{M}+\omega_{C} \cdot \alpha_{C}+\omega_{I} \cdot \alpha_{I}
\end{aligned}
$$

To model the dynamics of $\omega_{C}$ and $\omega_{I}$ a black-box approach was considered in the model. This approach features 3 suspended components: $X_{T S}, X_{m_{C}}$, and $X_{m_{I}}$. In addition, a total of four kinetically governed physical processes were included in the model approach: (1) cake layer build-up during filtration; (2) cake layer removal using biogas sparging to scour the membrane; (3) cake layer removal during back-flushing; 
and (4) irreversible fouling consolidation. Further details of this filtration model can be found in Robles et al. [36].

This filtration model features a total of 14 parameters that must be calibrated for each specific system. This model was previously validated and calibrated using experimental data obtained from the above-mentioned AnMBR plant. Model validation was performed by applying the revised version of the Morris screening method previously proposed by Ruano et al. [34] as GSA approach, and the need to include each of the proposed parameters in the model was assessed (Robles et al., [39]).

The model parameters were calibrated in a wide range of operating conditions (see Robles et al. [36]) and the calibrated values were used in this study.

\subsubsection{Objective functions of the supervisory controller}

The aim of dynamically optimising the inputs of the advanced controller was to minimise the operating costs and control error in each specific scenario. To this end, two different objective functions (outputs) were evaluated individually in order to assess the model-based supervisory controller in terms of (see step I and L in Figure 1b): controller performance (IAE, Eq. 8) and overall operating cost $\left(C_{\text {TOTAL }}\right.$, Eq. 14). Equation 8 was used to select the optimum combination of fuzzy-logic control parameters $(C T$, centre and amplitude of each input fuzzy set, and singleton value of each output fuzzy set) resulting in the lowest IAE. IAE is defined as the integral of the absolute error of the fouling rate in the simulated time series. $|F R E|$ is defined as the absolute error between the actual fouling rate and the respective set point. 
Equation 14 was used to identify the optimum combination of set points $\left(F R_{C_{-} S P}\right.$, $T M P_{M A X}, \% K_{20}$ and $S R F_{S P}$ ) for the advanced controller in order to minimise operating costs $\left(C_{\text {TOTAL }}\right) . C_{\text {TOTAL }}$ is defined as the average obtained during the 24-hour simulated time series. The unit chosen to evaluate the objective function was $V_{T}\left(\mathrm{~m}^{3}\right)$, taking into account both filtration (positive term) and back-flushing (negative term). Taking into account the main parameters that affect the costs of membrane technology [18, 40,41], the following terms were considered when defining this function: cost of membrane scouring by biogas sparging ( $€$ per $\mathrm{m}^{3}$ ); cost of pumping sludge through the membrane tank (€ per $\left.\mathrm{m}^{3}\right)$; cost of pumping permeate during filtration and back-flushing (€ per $\mathrm{m}^{3}$ ); cost of chemical reagent required to remove the corresponding irreversible fouling generated during filtration $\left(€\right.$ per $\left.\mathrm{m}^{3}\right)$; and cost of replacing membrane at end of membrane lifespan related to the respective irreversible fouling caused during filtration $\left(€\right.$ per $\mathrm{m}^{3}$ ). Unlike other studies (e.g. [6-9, 11, 12, 15]), this study did not consider the effluent quality index and effluent fines when evaluating the total AnMBR cost because the aim of the proposed supervisory controller is to optimise filtration operating and maintenance costs when operating under appropriate biological conditions. Moreover, previous results (data not shown) revealed that the quality of AnMBR effluent depends mainly on SRT at a given operating temperature rather than filtration conditions.

The operating cost of the blower (adiabatic compression), sludge recycling pump and permeate pump was calculated according to Judd and Judd [41] by applying Eq. 9, 10 and 11 , respectively. 
$C_{B}=\frac{M \cdot R \cdot T_{\text {gas }}}{(\alpha-1) \eta_{\text {blower }}}\left[\left(\frac{P_{2}}{P_{1}}\right)^{\frac{\alpha-1}{\alpha}}-1\right] \cdot \frac{E_{C O S T}}{V_{T}}$

where $C_{B}\left(€\right.$ per $\left.\mathrm{m}^{3}\right)$ is the operating cost of membrane scouring by biogas sparging, $M\left(\mathrm{~mol} \mathrm{~s}^{-1}\right)$ is the molar flow rate of biogas, $R\left(\mathrm{~kJ} \mathrm{~mol}^{-1} \mathrm{~K}^{-1}\right)$ is the gas constant for biogas, $P_{1}(\mathrm{~atm})$ is the absolute inlet pressure, $P_{2}(\mathrm{~atm})$ is the absolute outlet pressure, $T_{\text {gas }}(\mathrm{K})$ is the biogas temperature, $\alpha$ is the compression index, $\eta_{\text {blower }}$ is the overall mechanical and electrical efficiency of the blower, $E_{C O S T}(€$ per $\mathrm{kWh})$ is the cost of energy, and $V_{T}$ is the net volume of treated wastewater $\left(\mathrm{m}^{3}\right)$.

$E_{C O S T}$ was set to $€ 0.138$ per $\mathrm{kWh}$ in this study (as per current electricity rates and prices in Spain).

$C_{S R F}=q \cdot \rho_{\text {sludge }} \cdot g \frac{\left[\left(\frac{\left(L+L_{e q}\right) f \cdot V^{2}}{D \cdot 2 \cdot g}\right)_{\text {suc }}+\left(\frac{\left(L+L_{e q}\right) f \cdot V^{2}}{D \cdot 2 \cdot g}\right)_{d i s}\right]+\left[z_{1}-z_{2}\right]}{\eta_{\text {pump }}} \cdot \frac{E_{\text {COST }}}{V_{T}}$ (Eq. 10)

where $C_{S R F}\left(€\right.$ per $\left.\mathrm{m}^{3}\right)$ is the operating cost of pumping the sludge, calculated considering both pump suction (suc) and the pump discharge (dis), $q\left(\mathrm{~m}^{3} \mathrm{~s}^{-1}\right)$ is the volumetric flow rate, $\rho_{\text {sludge }}\left(\mathrm{kg} \mathrm{m}^{-3}\right)$ is the sludge density, $g\left(\mathrm{~m} \mathrm{~s}^{-1}\right)$ is the acceleration of gravity, $L(\mathrm{~m})$ is the pipe length, $L_{e q}(\mathrm{~m})$ is the equivalent pipe length of accidental pressure drops, $V\left(\mathrm{~m} \mathrm{~s}^{-1}\right)$ is the fluid velocity, $f$ is the friction factor, $D(\mathrm{~m})$ is the pipe diameter, $Z_{1}-Z_{2}(\mathrm{~m})$ is the difference in height, and $\eta_{\text {pump }}$ is the overall mechanical and electrical efficiency of the pump.

$$
C_{\text {stage }}=\frac{q_{\text {stage }} \cdot T M P_{\text {stage }}}{\eta_{\text {pump }}} \cdot \frac{E_{\text {COST }}}{V_{T}}
$$


where $C_{\text {stage }}\left(€\right.$ per $\left.\mathrm{m}^{3}\right)$ is the operating cost of pumping permeate during the respective operating stage (i.e. filtration or back-flushing), $T M P_{\text {stage }}(\mathrm{Pa})$ is the TMP during the respective operating stage (i.e. filtration or back-flushing), and $q_{\text {stage }}\left(\mathrm{m}^{3} \mathrm{~s}^{-1}\right)$ is the volumetric flow rate during the respective operating stage (i.e. filtration or backflushing).

As regards membrane cleaning, the proportional cost of the reagents needed to clean the irreversible fouling produced during filtration was contemplated when evaluating total operating costs (Eq. 12). $\Delta R_{I, M A X}$ was set to $10^{13} \mathrm{~m}^{-1}$ (established on the basis of experimental results). Two reagents were contemplated for cleaning the membranes: citric acid and $\mathrm{NaClO}$. The cleaning protocol considered consisted of a 5hour cleaning session with acid (2000 ppm of citric acid), $\mathrm{pH} 2.5$, followed by a 5-hour oxidising cleaning session (2000 ppm of $\mathrm{NaClO}$ ), pH 12.

$$
C_{R E A G E N T S}=\frac{\Delta R_{I, \text { filtration }}}{\Delta R_{I, \text { MAX }}} \cdot \frac{\left(X_{A C} \cdot A C_{C O S T}+X_{N a C l O} \cdot N a C l O_{C O S T}\right)}{V_{T}}
$$

where $C_{R E A G E N T S}\left(€\right.$ per $\left.\mathrm{m}^{3}\right)$ is the proportional cost of the reagents needed to clean the irreversible fouling produced during filtration, $\Delta R_{I, \text { filtration }}$ is the increase in the resistance caused by irreversible fouling during filtration, $X_{A C}(\mathrm{~kg}$ per cleaning) is the amount of citric acid required for membrane cleaning, $A C_{C O S T}(€$ per $\mathrm{kg}$ ) is the price of citric acid (constant), $X_{\mathrm{NaClO}}(\mathrm{kg}$ per cleaning) is the amount of $\mathrm{NaClO}$ required for membrane cleaning, and $\mathrm{NaClO}_{\mathrm{COST}}(€$ per kg) is the price of $\mathrm{NaClO}$ (constant).

As regards membrane lifespan, the cost of replacing the membrane was contemplated in order to evaluate the entire operating cost (Eq. 13). The maximum total contact with chlorine permissible before membrane replacement according to the 
supplier is 500,000 ppm-hours cumulative.

$$
C_{\text {LIFESPAN }}=\frac{\Delta R_{I, \text { filtration }} \cdot \frac{M_{C O S T} \cdot A / N_{C, M A X}}{\Delta R_{I, M A X}}}{V_{T}}
$$

where $C_{\text {LIFESPAN }}\left(€\right.$ per $\left.\mathrm{m}^{3}\right)$ is the cost of membrane replacement due to irreversible fouling, $M_{\operatorname{COST}}\left(€\right.$ per $\left.\mathrm{m}^{2}\right)$ is the price per square metre of membrane area, $A\left(\mathrm{~m}^{2}\right)$ is the membrane area, and $N_{C, M A X}$ is the maximum number of times the membrane can be cleaned $(50$ times $=500,000 \mathrm{ppm}$ of maximum accumulated chloride tolerance $/ 2000$ ppm of citric acid per cleaning / 5 hrs contact).

$N_{C, M A X}$ resulted in a value of 50 times in this study $\left(N_{C, M A X}=50\right.$ times $=500,000$ ppm of maximum accumulated chloride tolerance of the membrane used / $2000 \mathrm{ppm}$ of citric acid per cleaning / 5 hrs contact per cleaning). The prices of the membrane area and chemical reagents used in our full-scale calculations were those given by the respective suppliers.

On the basis of the different terms contemplated when evaluating total costs $\left(C_{\text {TоTAL }}, €\right.$ per $\left.\mathrm{m}^{3}\right)$, the following objective function was defined in this study:

$$
C_{\text {TOTAL }}=C_{B}+C_{\text {SRF }}+C_{\text {stage }}+C_{\text {REAGENTS }}+C_{\text {LIFESPAN }}
$$

\subsubsection{Morris screening method}

The Morris screening method [32] is a one-factor-at-a-time method of GSA that evaluates the $E E_{i}$ distribution of each input factor in a model upon each output, and 
produces basic statistics then used to gather sensitivity information. In this study the scaled elementary effect concept (i.e. $S E E_{i}$ ) proposed by Sin and Gernaey [42] was applied. $E E_{i}$ is in itself a local measure of sensitivity, but this drawback is overcome by repeating $E E_{i}$ calculations in the input region of interest using Morris's efficient random sampling strategy, which is obtained by using a trajectory-based design. This sampling strategy then evaluates the $E E_{i}$ of each input factor with the same step size but at different initial points in the input region of interest. Finally, the $F_{i}$ of the elementary effects of each input factor was analysed to determine the relative importance of the input factors and obtain a good approximation of a GSA.

In this study we applied the trajectory-based sampling strategy proposed in Ruano et al. [34] which consists of maximising distances between $r$ Morris trajectories that are selected from a defined group of $\mathrm{M}$ initial trajectories (i.e. maximising their dispersion in the input space). Further details of this sampling strategy can be found in Ruano et al. [34].

As proposed by Saltelli et al. [43], $\mu, \sigma$ and $\mu^{*}$ of the $S E E_{i}$ values of each distribution $F_{i}$ were considered in this study to be sensitivity measures.

In accordance with Campolongo et al. [44], $\mu$ and $\sigma$ must be evaluated simultaneously in order to assess stability rankings reliably because an input factor whose elementary effects have different signs would have a low $\mu$ but a considerable $\sigma$ (i.e. identifiable input factors affecting the output non-linearly or interactively). To overcome this problem, as suggested in Campolongo et al. [45], $\mu^{*}$ was used in this study to rank the input factors in order to determine the optimum number of times that 
the elementary effects should be calculated (i.e. $r_{\text {opt }}$ ). The $r_{\text {opt }}$ of each $F_{i}$ was calculated using a constant resolution of $p=4$. In order to identify $r_{o p t}, r$ was increased until the ranking of input factors remained nearly stable, i.e. the type II error was minimised (type II error means identifying an important factor as insignificant). This stability was evaluated numerically using a modified version of the $P F_{r i \rightarrow r j}$ position index put forward by Ruano et al. [34]. For given rankings obtained by $r_{i}$ and $r_{j}$, this modified index $P F_{r i \rightarrow r j}$ is defined by Eq. 15 .

$$
P F_{r_{i} \rightarrow r_{j}}=\sum_{k=1}^{k} \frac{\operatorname{Abs}\left(P_{k, i}-P_{k, j}\right)}{\mu_{P_{k, i}, P_{k, j}}} \cdot \frac{1}{P F_{M A X}}
$$

where $P_{k, i}$ is the position of the $k^{\text {th }}$ input factor in the ranking obtained by $r_{i} ; P_{k, j}$ is the position of the $k^{\text {th }}$ input factor in the ranking obtained by $r_{j} ; \mu_{P_{k, i}, P_{k, j}}$ is the average position of the $k^{\text {th }}$ input factor in the ranking obtained by $r_{i}$ and $r_{j}$; and $P F_{M A X}$ is the maximum value of $P F_{r i \rightarrow r j}$ for the number of input factors evaluated. $P F_{r i \rightarrow r j}$ is highest when two rankings are compared and found to present the highest factor spread. For instance, with 3 input factors and $P_{1, i}=1, P_{2, i}=2, P_{3, i}=3$ the maximum value of $\mathrm{PF}_{\mathrm{ri} \rightarrow \mathrm{r} j}$ occurs when $P_{1, i}=3, P_{2, i}=1, P_{3, i}=2$ [45]. When 19 input factors (fuzzy-logic control parameters) and 4 input factors (advanced controller set points) are considered, the maximum values of $\mathrm{PF}_{\mathrm{ri} \rightarrow \mathrm{rj}}$ are 19.56 and 3.33, respectively.

Since the value of the $P F_{r i \rightarrow r j}$ position index proposed by Ruano et al. [34] depends greatly on the number of input factors evaluated, we standardised the position index by including $P F_{M A X}$ (Robles et al., [39]). The intention of this modified position index $P F_{r i \rightarrow r j}($ Eq. 15) is to provide a general criteria for quantifying the convergence of the 
Morris screening method. Based on previous studies, we propose that the criterion for establishing $r_{j}$ as $r_{\text {opt }}$ is when two consecutive $P F_{r i \rightarrow r j}$ values below 0.3 are obtained.

Once $\mathrm{r}_{\mathrm{opt}}$ was found, the use of $\mu^{*}$ alone was not enough to identify the input factors that have linear and additive effects on the output because information about the impact of the sign was lost [44]. Therefore, the graphical Morris approach (using $\mu$ and $\sigma$ as sensitivity measures) was used to identify the highly-influential factors that have linear and additive effects on the output, which is desirable for automatic tuning. To this end, the values of $\mu$ and $\sigma$ obtained for all $S E E_{i}$ values of each $F_{i}$ are plotted together with two lines corresponding to $\mu_{i} \pm 2 S E M_{i}$, where $S E M_{i}$ is the standard error of the mean that can be calculated thus: $S E M_{i}=\sigma_{i} / \sqrt{r}$. Factors laying outside the wedge formed by the two lines defined by $\mu_{i}= \pm 2 S E M_{i}$ (with high $\mu$ and relatively small $\sigma$ ) are deemed in this study to be highly-influential because they have linear and additive effects on the output. Factors with small $\mu$ but high $\sigma$ inside this wedge are deemed to be influential and to have non-linear or interactive effects on the output (the factor conveys the effect of different signs, depending on the values of the other factors). The factors with small $\mu$ and $\sigma$ inside this wedge are deemed to be non-influential and to have a negligible impact on the output [32].

In this study, the Morris screening method was implemented in MATLAB ${ }^{\circledR}$. It was applied to different number of $r$, chosen from $M=1000$ initial Morris trajectories, until the ranking of significance remained nearly stable, as measured quantitatively by the index $P F_{r i \rightarrow r j}$. In this sensitivity study, two output variables were used: overall operating cost (Eq. 14), which was used to assess the sensitivity of the advanced controller due to changes in the set points (i.e. $F R_{C_{-} S P}, T M P_{M A X}, \% K_{20}$ and $S R F_{S P}$ ); and $I A E$ (Eq. 8), 
which was used to evaluate the sensitivity of the advanced controller due to changes in the fuzzy-logic control parameters. Therefore, Eq. 14 and Eq. 8 were used to optimise process cost and process performance over time, respectively.

In this study, the distribution of the elementary effects of each input factor in the model upon the corresponding output was evaluated by modifying all the input factors of the advanced controller, i.e. set points $\left(F R_{C_{-} S P}, T M P_{M A X}, \% K_{20}\right.$ and $\left.S R F_{S P}\right)$ and fuzzylogic control parameters ( $C T$, centre and amplitude for each input fuzzy set, and singleton value for each output fuzzy set). Nevertheless, two differentiated rankings were established in order to evaluate the influence of the different input factors: one featuring the set points and other, the fuzzy-logic control parameters.

\subsubsection{Monte Carlo method}

In order to optimise a controller, suitable initial values must be selected for input factors identified as highly-influential (i.e. with linear and additive effects on the output). In addition, the other factors (both influential and otherwise) must be set to adequate values in order to enhance the optimisation process. The Monte Carlo method based on trajectory-based random sampling was used in our study to select adequate values for all the input factors of the advanced controller. Hence, the combination of advanced controller set points and fuzzy-logic control parameters giving the minimum operating cost (Eq. 14) and minimum IAE (Eq. 8), respectively, was selected as the initial values of the model-based supervisory controller. This Monte Carlo method was applied to the different Morris simulations carried out in search of $r_{\text {opt }}$ because a suitable coverage of the input region was assumed. 


\subsubsection{Dynamic optimisation of the advanced control system}

The set points of the advanced control system were optimised by minimising $C_{\text {TOTAL }}$ (see Eq. 14) and using 6-hour simulations (see step J Figure 1b) during the different stages of membrane operations. As mentioned before, apart from optimising the set points of the controller, the fuzzy-logic control parameters had to be adjusted for each operating scenario. This step consisted of minimising IAE (see Eq. 8) and was carried out using 1-hour filtration-stage simulations (see step M in Figure 1b) since, as mentioned before, the fuzzy-logic controller only works during filtration. These 1-hour filtration-stage simulations included intakes with a $\mathbf{J}_{20}$ step to evaluate $I A E$ over time in each operating scenario. Since considerably shorter simulations were required for adjusting the fuzzy-logic control parameters, a cascade-based optimising methodology for the advanced control system was proposed in this study (see Figure 1b). In this methodology, the highly-influential fuzzy-logic control parameters are optimised for each combination of advanced controller set points (see Figure 1b, Step K). This cascade-based optimisation allows both fuzzy-logic control parameters and advanced controller set points to be adjusted simultaneously with moderate computational requirements (approx. 5 minutes).

Therefore, in the proposed cascade-based optimisation methodology, the primary optimisation loop uses $C_{T O T A L}$ as an objective function, whilst the secondary optimisation loop uses IAE. Both optimisation algorithms were applied using the subspace trust region method [46], based on the interior-reflective Newton method (implemented in MATLAB ${ }^{\circledR}$ LSQNONLIN function), and the Runge-Kutta method (MATLAB ${ }^{\circledR}$ ODE45 function). MATLAB ${ }^{\circledR}$ LSQNONLIN function solves nonlinear optimisation problems for a given objective function. In this study, the termination 
criteria of tolerance on both objective functions was set to $1 \%$.

\subsubsection{Simulation strategy}

MATLAB ${ }^{\circledR}$ was used in this study to simulate the above-mentioned filtration model. The Runge-Kutta method (MATLAB ${ }^{\circledR}$ ode45 function) was selected as the integration method.

\subsubsection{Morris screening method and Monte Carlo method}

The simulation strategy applied to the Morris screening method and the Monte Carlo method entailed 24 hours of continuous operation and was conducted using data for the following dynamic operating scenarios: $17 \mathrm{~g} \mathrm{~L}^{-1}$ of MLTS entering the membrane tank; BRF from approx. 4 to $12 \mathrm{Nm}^{3} \mathrm{~h}^{-1}$; and $\mathbf{J}_{20}$ from approx. 4 to $12 \mathrm{LMH}$. The dynamics of $\mathbf{J}_{20}$ considered the fluctuations typical in the intake of WWTPs. For this purpose, the standard dry weather influent records (updated in 2006) recommended by Copp [47] were used as shown in Robles et al. [30].

Table 1 shows the default values of the inputs to the advanced control system and the uncertainty used in the sensitivity analysis. Because the optimum combination of input values is uncertain, all the control input factors were varied according to a uniform distribution (similar to previous studies) with an uncertainty equal to $50 \%$ of the default value. The default values and the uncertainty factor for the advanced controller set points were established on the basis of our technical knowledge of the process and the operating constraints associated with process and controller performance [30]. The uncertainty factor for the fuzzy-logic control parameters was selected taking into 
account that the set points of the advanced control system were also modified in the simulations.

\subsubsection{Model-based supervisory controller}

The performance of the model-based supervisory controller was assessed by running the above-mentioned filtration model for 24 hours continuously. In order to validate this supervisory controller, the MLTS entering the membrane tank was set to 20 $\mathrm{g} \mathrm{L}^{-1}$ whilst $\mathrm{J}_{20}$ varied according to the dynamics typical of WWTP intake.

In this study, $O T$ was set to 1 hour. The overall computational cost for dynamically optimising the advanced controller was around 5 minutes (using a PC with $8 \mathrm{GHz}$ Intel ${ }^{\circledR}$ $\mathrm{CORE}^{\mathrm{TM}} \mathrm{i} 5$ processor).

\section{Results and discussion}

\subsection{Sensitivity analysis results}

Table 2 shows the resulting $\mu^{*}$ of the fuzzy-logic control parameters. As can be seen in this table, an increase in $r$ resulted in a greater similarity between the sensitivity measures of these input factors (see, for instance, the positions of $C T$ and FREaP in the significance rankings). Table 3 shows the $P F_{r i \mathrm{i}} r$ of the different number of trajectories evaluated. $P F_{r i \rightarrow r j}$ tended to decrease as the number of runs increased (from 50 to 90 ), which indicates a greater similarity between the positions of the factors in the compared rankings. This reveals that, as regards this fuzzy-logic control, low values of $r$ did not enable a suitable estimate of sensitivity measures because either the system was very 
non-linear or the factors involved considerable uncertainty. It is therefore necessary to find an appropriate $r$ in order to avoid type I and type II errors (false positive and false negative, respectively). For instance, in this study, when $r=60, C T$ was $10^{\text {th }}$ in the sensitivity ranking, whereas when $r=80$, it was $3^{\text {rd }}$.

As mentioned earlier, achieving two consecutive $P F_{r i \rightarrow r j}$ values below 0.3 was established in this study as the criterion for establishing $r_{j}$ as $r_{\text {opt }}$. In this respect, $P F_{r i \rightarrow r j}$ was 0.3 when $r$ was increased (from 70 to 80) but remained below this threshold when $r$ was higher (80 to 90). Therefore, $r=80$ was selected as $r_{\text {opt }}$ for evaluating the fuzzy logic controller. These results tally with previous studies of similar fuzzy-logic controllers [32]. When $r_{\text {opt }}=80$, the overall cost of evaluating the model was 1920 simulations ( simulations $=r \cdot(k+1) ; r=80 ; k=23)$. The computational cost of one simulation (involving 24 hours of operation) was approximately 1 minute when using a PC with $8 \mathrm{GHz}$ Intel ${ }^{\circledR} \mathrm{CORE}^{\mathrm{TM}}$ i5 processor.

Figure 2a shows the graphical Morris approach (using $r=80$ ) applied to evaluate the sensitivity of the fuzzy-logic controller. In this case, 3 factors were identified as highly influential with linear and additive effects on the output (their sensitivity measures lay outside the wedge formed by the two lines plotted according to $\mu_{i}=$ $\left.\pm 2 S E M_{i}\right)$ : (1) positive membership function centre of the accumulated $F R_{C}$ error (FRAEcP, $\mu=0.507$ and $\sigma=2.254$ ); (2) high positive singleton value of the increase in $B R F(V B R F s H P, \mu=0.532$ and $\sigma=1.741)$; and (3) control time $(C T, \mu=-0.671$ and $\sigma=$ 1.887). These results tally with our experienced-based knowledge about control systems of this type, since $C T$ is usually recognised as one of the most important parameters. High $C T$ values would result in a slow response to changes in process variables, whilst 
low values might cause an overly fast response resulting in instabilities. VBRFs $H P$ is important in the control system because it enables $B R F$ to respond quickly to increasing fouling rates. The value of $F R A E c P$ is important because it can identify possible increases in reversible fouling on the membrane surface. It is important to mention that the build-up of reversible fouling affects not only the operating costs of filtration, but also the cost of membrane chemical cleaning and membrane replacement due to higher propensities to irreversible fouling (high reversible fouling usually means high propensities to irreversible fouling).

The other factors lay inside the wedge formed by the two lines plotted according to $\mu_{i}= \pm 2 S E M_{i}$ and their impact on the output was therefore classified as either non-linear or interactive, or non-influential.

Table 4 shows the resulting $\mu^{*}$ of the advanced controller set points. As can be seen in this table, an increase in the number of elementary effect calculations (i.e. an increase in $r$ ) also modified the sensitivity measures of these input factors. Table 5 shows the $P F_{r i \rightarrow r j}$ values of the different $r$ values evaluated. As Table 5 shows, $P F_{r i \rightarrow r j}$ was zero when $r$ was increased from 10 to 20 . However, $P F_{r i \rightarrow r j}$ increased above the established threshold value (0.3) when $r$ was increased from 20 to 30. Therefore, values of $r$ below 20 resulted in this instance in type I and type II errors (false positive and false negative, respectively). On the other hand, $P F_{r i \rightarrow r j}$ fell below 0.3 when $r$ was increased from 30 to 40, and remained below this threshold when $r$ was higher (40 to 50). Therefore, $r=40$ was selected as $r_{\text {opt }}$ for evaluating the advanced controller set points.

Figure $2 \mathrm{~b}$ shows the graphical Morris approach (using $r=40$ ) adopted to evaluate the sensitivity of the advanced controller at the four set points. As mentioned earlier, 
this Morris approach was used to identify the influential factors with linear and additive effects on the output, which lay outside the wedge formed by two lines plotted according to $\mu_{i}= \pm 2 S E M_{i}$. Three of these 4 input factors were identified as highly influential: (1) $F R_{C_{-} S P}(\mu=2.650$ and $\sigma=0.645)$; (2) $S R F_{S P}(\mu=-0.175$ and $\sigma=0.225)$; and (3) $T M P_{M A X}(\mu=-0.117$ and $\sigma=0.306)$. The results shown in Figure $2 b$ tally with our knowledge of the process. $F R_{C_{-} S P}$ is the most important control set point due to its final impact on overall operating costs. High $F R_{C_{-} S P}$ values result in low membrane scouring costs, but higher chemical cleaning costs and membrane replacement costs due to a higher fouling propensity. On the other hand, operating at low $F R_{C_{-} S P}$ values requires high gas sparging intensities in order to minimise cake-layer build-up, which, consequently, minimises the cost of membrane chemical cleaning and membrane replacement due to a lower fouling propensity. $T M P_{M A X}$ is important because it affects the energy required to pump permeate (i.e. an increase in TMP increases the energy needed to pump permeate). However, $T M P_{M A X}$ also determines the start of backflushing, i.e., the higher the $T M P_{M A X}$, the lower the back-flushing frequency. Hence, it is also necessary to optimise the value of this parameter. The value of $S R F_{S P}$ is important because it affects not only the cost of pumping sludge through the membrane tank, but also the energy needed to minimise the build-up of cake. In this respect, $S R F_{S P}$ determines $M L T S_{M T}$ at a given $\mathrm{J}_{20}$, thus affecting the energy required for membrane scouring (i.e. an increase in $M L T S_{M T}$ means an increase in $B R F_{S P}$ at a given $F R_{C_{-} S P}$ ).

Only one advanced controller set point lay inside the wedge formed by the two lines plotted according to $\mu_{i}= \pm 2 S E M_{i}: \% K_{20}$. This was attributed to the interactive effects between $T M P_{M A X}$ and $\% K_{20}$ (i.e. both of them determine when back-flushing starts). In this respect, the impact of $\% K_{20}$ on the output was contemplated implicitly on 
the effect of $T M P_{M A X}$. Nevertheless, $\% K_{20}$ was originally included in the advanced control system because it adjusts the back-flushing frequency by taking into account fluctuations in membrane permeability over time and not merely a single fixed threshold value (e.g. $\left.T M P_{M A X}\right)$. $T M P_{M A X}$ was originally defined as the security threshold.

According to the results shown in Table 3 and Table 5, it is important to highlight that the optimum number of paths is closely related to the number of input factors involvedin the Morris screening application. The higher the number of input factors, the higher the number of paths required. These results tally with previous studies of Morris screening (see, for instance, $[34,45])$.

\subsection{Monte Carlo method results}

As mentioned before, the Monte Carlo method was used to select the initial values of the inputs to the advanced control system (including set points and fuzzy-logic control parameters).

As regards the advanced controller set points, considerable variations were observed in the total operating cost of the simulations conducted in this study. They ranged from $€ 0.052$ to 0.505 per $\mathrm{m}^{3}$ depending on the set-point value combination. Therefore, considerable energy savings could be made by selecting adequate initial values for these factors.

As regards the fuzzy-logic control, adequate initial values must be selected for the control factors in order to reduce $I A E$ and fine-tune the controller. In this respect, although most of the simulations resulted in low IAE values, it was observed that IAE 
rose from 0.013 to 7.728 when inadequate combinations of these factors were selected.

The combination of factors selected by the Monte Carlo method is shown in Table 1 (those values giving the lowest output variables, IAE and operating costs). Although this method does not give the optimum combination of inputs, because it is based on a discrete search, the output variables were at least partly optimised after a global search (based on trajectory-based random sampling). From this initial point in the input space, further optimisation was carried out by modifying the influential factors with linear and additive effects on the output (deemed in this study to be highly influential), as explained in the following section.

\subsection{Performance of model-based supervisory controller}

\subsubsection{Optimisation of fuzzy-logic controller}

Figure 3 shows the evolution of the optimised values of the fuzzy-logic control parameters identified as highly-influential using the Morris screening method. As mentioned before, the fuzzy-logic control parameters were calibrated over time to finetune the advanced controller. Figure 3 shows that the greatest set-point modification occurred during the operating period when daily $J_{20}$ was highest (see hours 10 to 13 in Figure 4a). In this respect, it is important to highlight that the operating $J_{20}$ affects not only the daily net volume of treated water, but also the operating costs (e.g. the energy needed for membrane scouring). Therefore, it is essential to optimise the performance of the fuzzy-logic controller periodically in order to enhance the performance of the advanced control system. 


\subsubsection{Optimisation of set points of advanced controller}

Figure 4 shows the optimised values for the advanced controller set points identified as highly-influential using the Morris screening method, as well as the simulation results of the main operating variables when using the model-based supervisory controller.

Figure 4a shows the evolution of $S R F_{S P}, M L T S_{M T}$ and $J_{20}$. As this figure shows, the behaviour of $S R F_{S P}$ was similar to $J_{20}$ but this evolution was not proportional. In this respect, the model-based supervisory controller set $S R F_{S P}$ to a value that allowed total operating costs to be minimised whilst taking the values of the other control set points into account (i.e. $F R_{C_{-} S P}$ and $T M P_{M A X}$ ). Indeed, the supervisory controller optimised $S R F_{S P}$ in order to establish adequate $M L T S_{M T}$ levels (see Figure 4a) that minimise the energy required not only for pumping sludge, but also for gas sparging and filtration.

Figure $4 \mathrm{~b}$ shows the evolution of $F R_{C_{-} S P}, F R_{C}$ and $B R F$. It can be seen that the highest $F R_{C_{-} S P}$ occurred in hours 2 to 9 , when the minimum $J_{20}$ was applied. This made it possible to reduce the operating $B R F$ considerably with no significant increase in $F R_{C}$. On the contrary, the lowest $F R_{C_{-} S P}$ was applied when operating at high $J_{20}$ values (see Figure 4a) since a reduction in fouling enables irreversible fouling to be minimised and therefore the membrane lifespan to be maximised. As Figure $4 \mathrm{~b}$ shows, the controller operated most of the time at the minimum threshold value established for $B R F\left(4 \mathrm{Nm}^{3}\right.$ $\left.\mathrm{h}^{-1}\right)$. From 0.5 to 9 hours, excessive gas sparging was used to scour the membrane because the minimum $B R F$ was reached, and this prevented the controller from setting $F R_{C}$ to the expected set point. In these conditions, the supervisory controller suggests that operating with intermittent gas sparging would be the best option (it was not 
considered in this study). Working with intermittent gas sparging would decrease operating costs considerably whilst allowing the advanced controller to set $F R_{C}$ to the set point established by the model-based supervisory controller. Between hours 10.5 and 11.5 , on the other hand, $B R F$ reached its maximum established value $\left(14 \mathrm{Nm}^{3} \mathrm{~h}^{-1}\right)$. During this period $F R_{C}$ increased because it was not possible to maintain the controlled variable around its set point. Nevertheless, the controller performed properly, i.e. the fouling rate remained close to its set point, when there were no constraints on the gas sparging intensity.

Figure $4 \mathrm{c}$ shows the evolution of $T M P_{M A X}, T M P$ and the membrane operating phase. It is important to emphasise that the model-based supervisory controller modified the back-flushing frequency (indirectly set by $T M P_{M A X}$ ) according to variations in operating conditions. Hence, a higher back-flushing frequency was established when operating at high $J_{20}$ and $M L T S_{M T}$ levels (see hours 9.5 to 11.5 in Figure 4a) in order to minimise irreversible fouling (directly affected by reversible fouling). Figure $4 \mathrm{c}$ shows that from hours 10 to 11.5 the established $T M P_{M A X}$ was exceeded. This highlights the capability of the model-based supervisory controller to identify system constraints. In this respect, $T M P_{M A X}$ was exceeded in order to fulfil the minimum filtration time set point needed to start back-flushing (set to $200 \mathrm{~s}$ in this study). During this operating period the gas sparging intensity related to the maximum operating $B R F$ was reached. Therefore, the fuzzy-logic controller was not able to set $F R_{C}$ to the expected set point, which resulted in $T M P_{M A X}$ being exceeded.

\subsection{Overall performance}

Figure 5 shows the evolution of the theoretical energy requirements and operating 
costs (related to filtration) of the simulated AnMBR system when the model-based supervisory controller was running.

Figure 5a shows the evolution of $W_{\text {TOTAL }}, W_{B}, W_{S R F}, W_{\text {filtration }}$ and $W_{\text {back-flushing. As }}$ this figure shows, the behaviour of $W_{\text {TOTAL }}$ was similar to $\mathrm{J}_{20}$. From hours 0.5 to 9 , Figure 5a illustrates an increase in $W_{T O T A L}$ despite a decrease in $\mathbf{J}_{20}$. As mentioned before, from hours 0.5 to 9 the controller was not able to set $F R_{C}$ to the expected set point due to operating at the minimum threshold established for $B R F\left(4 \mathrm{Nm}^{3} \mathrm{~h}^{-1}\right)$. Therefore, during this period the process performance was not optimised, resulting in an increase in $W_{B}$ due to an increase in the ratio between blower energy consumption and the net volume of treated wastewater, which confirms the advisability of using intermittent gas sparging in this study. On the other hand, a considerable decrease in $W_{\text {TOTAL }}$ was observed from hours 10.5 to 11.5 (see Figure 5a). In this case, the controller could not set $F R_{C}$ to the expected set point either - due to operating at the maximum $B R F$ threshold $\left(14 \mathrm{Nm}^{3} \mathrm{~h}^{-1}\right)$. This behaviour resulted in a decrease in the ratio between blower energy consumption and net volume of treated wastewater due to an increase in $\mathrm{J}_{20}$ whilst maintaining a constant $B R F$, resulting in a considerable decrease in $W_{B}$. However, it must be said that during this operating period the membranes operated at $F R$ values higher than the optimal value, thereby increasing the propensity to irreversible fouling. A higher propensity to irreversible fouling leads to higher operating costs as regards membrane chemical cleaning and membrane replacement.

The average energy consumption of the plant when the proposed supervisory controller was running was $0.17 \mathrm{kWh} \mathrm{m}^{-3}$. On the basis of this figure, the energy requirements for membrane scouring, sludge pumping and permeate pumping (including filtration and back-flushing) were $0.12,0.04$ and $0.01 \mathrm{kWh} \mathrm{m}^{-3}$, respectively. 
Membrane scouring accounted for a considerable part of total energy requirements, which highlights the need to optimise the intensity of gas sparging in each operating scenario. Indeed, the average energy needed to pump sludge and permeate was similar to the energy needed when the advanced controller was running alone in similar conditions (about $0.04 \mathrm{kWh} \mathrm{m}^{-3}$ ); whilst the average energy for membrane scouring was considerably reduced (from about 0.16 to $0.12 \mathrm{kWh} \mathrm{m}^{-3}$ ). Therefore, energy savings of up to $25 \%$ in membrane scouring can be achieved by this model-based real time supervisory controller. In addition, as mentioned before, these energy savings could be increased if intermittent gas sparging was incorporated into the advanced control system.

On the other hand, the model-based supervisory controller established a total downtime for physical cleaning of approximately $2.4 \%$ of operating time, which is slightly higher than when the advanced controller was running alone. This was because not only energy consumption but also membrane cleaning and membrane replacement were optimised (i.e. an increase in the frequency of physical cleaning often means a reduction in the fouling propensity).

Figure $5 \mathrm{~b}$ shows the evolution of $C_{T O T A L}, C_{W}, C_{R E A G E N T S}$ and $C_{\text {LIFESPAN. As expected, }}$ operating costs behave like energy requirements. In this study, the average operating cost of the AnMBR after implementing the proposed model-based supervisory controller was about $€ 0.045$ per $\mathrm{m}^{3}$, of which about $53.3 \%$ was the cost of energy (about $€ 0.024$ per $\mathrm{m}^{3}$ ). These results highlight the need to optimise short-term membrane filtration because it could determine the feasibility of using AnMBR technology to treat urban wastewater. 
The performance of the proposed model-based supervisory controller showed that far greater energy savings could be achieved by using the proposed model-based supervisory controller in conjunction with the advanced controller rather than using the latter alone. The proposed supervisory control system enables adequate filtration and can be adapted to new operating requirements. Moreover, the proposed supervisory controller fulfils the main requirements of real-time optimisation [48]: (1) robustness (i.e. it always finds a solution); (2) fast problem solving; (3) in certain operating conditions, it always reaches the same solution, even from different starting points; and (4) ability to identify system constraints.

\section{Conclusions}

This paper describes a model-based method for optimising filtration in submerged AnMBRs that considers three statistical methods: (1) sensitivity analysis (Morris screening method); (2) Monte Carlo method (trajectory-based random sampling); and (3) optimisation algorithm (performing as supervisory controller). The Morris screening method enabled influential control factors to be identified. The Monte Carlo method enabled suitable initial values to be selected for all the input factors of the advanced controller. The optimisation algorithm enabled the advanced controller to be enhanced with moderate computational requirements (approx. 5 minutes) by minimising operating costs. The theoretical energy consumption of the AnMBR when running the proposed supervisory controller was $0.17 \mathrm{kWh} \mathrm{m}^{3}$. Energy savings of up to $25 \%$ were achieved during membrane scouring in comparison with using the advanced controller alone. The downtime for physical cleaning was approx. $2.4 \%$ of operating time. The average operating cost of the AnMBR system after implementing the proposed supervisory controller was approx. $€ 0.045$ per $\mathrm{m}^{3}$, of which approx. $53.3 \%$ were energy costs. In 
addition, the proposed supervisory controller fulfils the main requirements for real-time optimisation, i.e. robustness (i.e. it can always find a solution), fast problem solving, consistent conversion, and ability to identify system constraints.

\section{Acknowledgements}

This research work has been supported by the Spanish Ministry of Science and Innovation (MICINN, Projects CTM2008-06809-C02-01/02 and FPI grant BES-2009023712) and the Spanish Ministry of Economy and Competitiveness (MINECO, Projects CTM2011-28595-C02-01/02), jointly with the European Regional Development Fund (ERDF) and Generalitat Valenciana GVA-ACOMP2013/203, which are gratefully acknowledged.

\section{References}

[1] W. Naessens, T. Maere, I. Nopens, Critical review of membrane bioreactor models - Part 1: Biokinetic and filtration models, Bioresour. Technol. 122 (2012) 95 - 106.

[2] G. Mannina, G. Di Bella, G. Viviani, An integrated model for biological and physical process simulation in membrane bioreactors (MBRs), J. Membrane Sci. 376 (2011), 56 - 69.

[3] J. Ferrer, J.J. Morenilla, A. Bouzas, F. García-Usach, Calibration and simulation of two large wastewater treatment plants operated for nutrient removal, Water Sci. Technol. 50 (2004), 87 - 94.

[4] K. Derbal, M. Bencheikh-lehocine, F. Cecchi, A.-H. Meniai, P. Pavan, Application of the IWA ADM1 model to simulate anaerobic co-digestion of organic waste with waste activated sludge in mesophilic condition, Bioresour. Technol. 100 (2009), 1539 - 1543.

[5] M.V. Ruano, J. Serralta, J. Ribes, F. Garcia-Usach, A. Bouzas, R. Barat, A. Seco, J. Ferrer, Application of the General Model "Biological Nutrient Removal Model No.1" to upgrade two full-scale WWTPs, Environ. Technol. 33(2012), 1005 - 1012.

[6] X. Flores-Alsina, I. Rodriguez-Roda, G. Sin, K.V. Gernaey, Multi-criteria evaluation of wastewater 
treatment plant control strategies under uncertainty, Water Res. 42 (2008), 4485 - 4497.

[7] L. Benedetti, B. De Baets, I. Nopens, P.A. Vanrolleghem, Multi-criteria analysis of wastewater treatment plant design and control scenarios under uncertainty, Environ. Mod. Soft. 25 (2010), 616 621.

[8] X. Flores-Alsina, A. Gallego, G. Feijoo, I. Rodriguez-Roda, Multiple-objective evaluation of wastewater treatment plant control alternatives, J. Environ. Manage. 91 (2010), 1193 - 1201.

[9] G. S. Ostace, J. A. Baeza, J. Guerrero, A. Guisasola, V. M. Cristea, P. S. Agachi, J. Lafuente, Development and economic assessment of different WWTP control strategies for optimal simultaneous removal of carbon, nitrogen and phosphorus, Comput. Chem. Eng. 53 (2013) 164- 177.

[10] B. Beraud, J.P. Steyer C. Lemoine, E. Latrille, Optimization of WWTP control by means of multiobjective genetic algorithms and sensitivity analysis, $18^{\text {th }}$ European Symposium on Computer Aided Process Engineering - ESCAPE 18 (2008), 539 - 544.

[11] J. Guerrero, A. Guisasola, R. Vilanova, J.A. Baeza, Improving the performance of a WWTP control system by model-based setpoint optimisation, Environ. Mod. Soft. 26 (2011), 492 - 497.

[12] J. Guerrero, A. Guisasola, J. Comas, I. Rodriguez-Roda, J.A. Baeza, Multi-criteria selection of optimum WWTP control setpoints based on microbiology-related failures, effluent quality and operating costs, Chem. Eng. J. 188 (2012), 23 - 29.

[13] A.N.L. Ng, A.S. Kim, A mini-review of modeling studies on membrane bioreactor (MBR) treatment for municipal wastewaters, Desalination 212 (2007), $261-281$.

[14] G. Ferrero, I. Rodríguez-Roda, J. Comas, Automatic control systems for submerged membrane bioreactors: A state-of-the-art review, Water Res. 46 (2012), 3421 - 3433.

[15] G. Mannina, A. Cosenza, The fouling phenomenon in membrane bioreactors: Assessment of different strategies for energy saving, J. Membr. Sci. 444 (2013), 332 - 344.

[16] G. Mannina, G. Di Bella, G. Viviani, An integrated model for biological and physical process simulation in membrane bioreactors (MBRs), J. Membrane Sci. 376 (2011), 56 - 69.

[17] A. Cosenza, G. Mannina, M.B. Neumann, G. Viviani, P.A. Vanrolleghem, Biological nitrogen and phosphorus removal in membrane bioreactors: model development and parameter estimation, Bioprocess Biosyst. Eng. 36 (2013), 499 - 514.

[18] T. Maere, B. Verrecht, S. Moerenhout, S. Judd, I. Nopens, BSM-MBR: a benchmark simulation model to compare control and operational strategies for membrane bioreactors, Water Res. 45(2011), $2181-2190$. 
[19] J.B. Copp. The COST Simulation Benchmark: Description and Simulator Manual. Office for Official Publications of the European Community, Luxembourg (2002).

[20] S. Gabarrón, G. Ferrero, M. Dalmau, J. Comas, I. Rodriguez-Roda, Assessment of energy-saving strategies and operational costs in fullscale membrane bioreactors J. Environ. Manage. 134 (2014), 8 14.

[21] A. Drews, H. Arellano-Garcia, J. Schöneberger, J. Schaller, M. Kraume, G. Wozny, Improving the efficiency of membrane bioreactors by a novel model-based control of membrane filtration, $17^{\text {th }}$ European Symposium on Computer Aided Process Engineering - ESCAPE 17(2007), 345 - 350.

[22] A. Drews, H. Arellano-Garcia, J. Schöneberger, J. Schaller, G. Wozny, M. Kraume, Model-based recognition of fouling mechanisms in membrane bioreactors, Desalination 236 (2009), 224 - 233.

[23] J. Busch, A. Cruse, W. Marquardt, Run-to-Run Control of Membrane Filtration Processes, AIChE J. 53 (2007), $2316-2328$.

[24] C. Huyskens, E. Brauns, E. Van Hoof, L. Diels, H. De Wever, Validation of a supervisory control system for energy savings in membrane bioreactors, Water Res. 45 (2011), 1443 - 1453.

[25] C. Huyskens, E. Brauns, E. Van Hoof, H. De Wever, A new method for the evaluation of the reversible and irreversible fouling propensity of MBR mixed liquor, J. Membr. Sci. 323 (2008), 185 192.

[26] G. Ferrero, H. Monclús, G. Buttiglieri, S. Gabarron, J. Comas, I. Rodriguez-Roda, Development of a control algorithm for air-scour reduction in membrane bioreactors for wastewater treatment, J. Chem. Technol. Biotechnol. 86 (2010), $784-789$.

[27] G. Ferrero, H. Monclús, G. Buttiglieri, J. Comas, I. Rodriguez-Roda, Automatic control system for energy optimization in membrane bioreactors, Desalination 268 (2011), 276 - 280.

[28] G. Ferrero, H. Monclús, L. Sancho, J.M. Garrido, J. Comas, I. Rodriguez-Roda, A knowledge-based control system for air-scour optimisation in membrane bioreactors, Water Sci. Technol. 63 (2011), 2025 -2031 .

[29] R. Soleimani, N.A. Shoushtari, B. Mirza, A. Salahi, Experimental investigation, modeling and optimization of membrane separation using artificial neural network and multi-objective optimization using genetic algorithm, Chem. Eng. Res. Des. 91 (2013), 883 - 903.

[30] A. Robles, M.V. Ruano, J. Ribes, J. Ferrer, Advanced control system for optimal filtration in submerged anaerobic MBRs (SAnMBRs), J. Membrane Sci. 430 (2013), 330 - 341.

[31] K.J. Åström, T. Hägglund, C.C. Hang, W.K. Ho, Automatic tuning and adaptation for PID 
controllers - a survey, Control Engineering Practice 1(1993), 699-714.

[32] M. Morris, Factorial sampling plans for preliminary computational experiments, Technometrics. 33 (1991), $239-245$.

[33] M.V. Ruano, J. Ribes, J. Ferrer, G. Sin, Application of the Morris method for screening the influential parameters of fuzzy controllers applied to WWTPs. Wat. Scien. Tech. 63 (2011), 2199 2206.

[34] M.V. Ruano, J. Ribes, A. Seco, J. Ferrer, An improved sampling strategy based on trajectory design for the application of Morris method to systems with many input factors, Environ. Mod. Soft. 37 (2012), $103-109$.

[35] M.V. Ruano, J. Ribes, G. Sin, A. Seco, J. Ferrer, A systematic approach for fine-tuning of fuzzy controllers applied to WWTPs, Environ. Mod. Soft. 25 (2010), 670 - 676.

[36] A. Robles, M.V. Ruano, J. Ribes, A. Seco, J. Ferrer, A filtration model applied to submerged anaerobic MBRs (SAnMBRs), J. Membrane Sci. 444(2013), 139 - 147.

[37] A. Robles, M.V. Ruano, J. Ribes, J. Ferrer, Factors that affect the permeability of commercial hollow-fibre membranes in a submerged anaerobic MBR (HF-SAnMBR) system, Water Res. 47 (2013), $1277-1288$.

[38] American Public Health Association/American Water Works Association/Water Environmental Federation, Standard methods for the Examination of Water and Wastewater, $21^{\text {st }}$ edition, Washington DC, USA, 2005.

[39] A. Robles, M.V. Ruano, J. Ribes, A. Seco, J. Ferrer, Global sensitivity analysis of a filtration model for submerged anaerobic membrane bioreactors (AnMBR). Bioresour. Technol. (2014), http://dx.doi.org/10.1016/j.biortech.2014.02.087

[40] B. Verrecht, T. Maere, I. Nopens, C. Brepols, S. Judd, The cost of a large-scale hollow fibre MBR, Water research 44 (2010), $5274-5283$.

[41] S. Judd, C. Judd, The MBR Book: Principles and Applications of Membrane Bioreactors for Water and Wastewater Treatment, second ed., Elsevier, ISBN: 978-0-08-096682-3, 2011.

[42] G. Sin, KV. Gernaey, Improving the Morris method for sensitivity analysis by scaling the elementary effects, In: proceedings of the 19th European Symposium on Computer Aided Process Engineering (ESCAPE 19), Elsevier (2009), 925 - 930.

[43] A. Saltelli, S. Tarantola, F. Campolongo, M. Ratto, Sensitivity analysis in practice: a guide to assessing scientific models, Chicester: Wiley (2004). 
[44] F. Campolongo, J. Cariboni, A. Saltelli, An effective screening design for sensitivity analysis of large models. Environ. Mod. Soft. 22 (2007), 1509 - 1518.

[45] A. Cosenza, G. Mannina, P.A. Vanrolleghem, M.B. Neumann, Global sensitivity analysis in wastewater applications: a comprehensive comparison of different methods. Environ. Mod. Soft. 49 (2013), $40-52$.

[46] T.F. Coleman, Y. Li, An interior, trust region approach for nonlinear minimization subject to bounds. SIAM J. Optim. 6 (1996), $418-445$.

[47] J.B. Copp, Development of standardised influent files for the evaluation of activated sludge control strategies, IAWQ Scientific and Technical Report Task Group: Respirometry in Control of the Activated Sludge Process - internal report, 1999.

[48] G. Towler, R.K. Sinnott, Chemical Engineering Design: Principles, Practice and Economics of Plant and Process Design, second ed., Elsevier Science, ISBN: 978-0-08-096659-5, 2012.

\section{Figure and table captions}

Figure 1. (a) Flow chart of proposed methodology for real-time optimisation of filtration in submerged AnMBRs. (b) Flow chart of model-based supervisory controller.

Figure 2. Sensitivity analysis results of: (a) fuzzy-logic control parameters ( $\mu$ versus $\sigma$ when final value of $r=80$ ); and (b) advanced controller set points ( $\mu$ versus $\sigma$ when final value of $r=40$ ). Lines plotted according to $\mu_{i}= \pm 2 S E M_{i}$.

Figure 3. Evolution of optimised values of fuzzy-logic control parameters identified as highly-influential using the Morris screening method.

Figure 4. Optimised values of advanced controller set points identified as highly-influential using the Morris screening method and modelled results of main operating variables when the model-based supervisory controller was running. Evolution of: (a) $S R F_{S P}, M L T S_{M T}$ and $J_{20}$; (b) $F R_{C_{-} S P}, F R_{C}$ and $B R F$; and (c) $T M P_{M A X}, T M P$ and membrane operating stage.

Figure 5. Model-based supervisory control performance. Evolution of: (a) $W_{T O T A L}, W_{B}, W_{S R F}, W_{\text {filtration }}$ and $W_{\text {back-flushing }}$; and (b) $C_{\text {TOTAL }}, C_{W}, C_{R E A G E N T S}$ and $C_{\text {LIFESPAN. }}$

Table 1. Input factors (including advanced controller set points and fuzzy-logic control parameters): default values, interval of variation or uncertainty, respectively, and initial values of model-based 
supervisory controller [30]. **corresponding to dynamically optimised inputs identified as influential. Acronyms for each fuzzy-logic parameter (rows 6 to 23) are defined in section 2.2.2.3. Fuzzy-logic controller description.

Table 2. Sensitivity analysis results of fuzzy-logic control parameters: sensitivity measures at different values of $r$. Acronyms for each fuzzy-logic parameter are defined in section 2.2.2.3. Fuzzy-logic controller description.

Table 3. Sensitivity analysis results of fuzzy-logic control parameters: position factors $\left(P F_{r i} \rightarrow r j\right)$ at different variations in $r$.

Table 4. Sensitivity analysis results of advanced controller set points: sensitivity measures at different values of $r$.

Table 5. Sensitivity analysis results of advanced controller set points: position factors $\left(P F_{r i} \rightarrow r j\right)$ at different variations in $r$. 
Table 1. Input factors (including advanced controller set points and fuzzy-logic control parameters): default values, interval of variation or uncertainty, respectively, and initial values of model-based supervisory controller [30]. **corresponding to dynamically optimised inputs identified as influential. Acronyms for each fuzzy-logic parameter (rows 6 to 23) are defined in section 2.2.2.3. Fuzzy-logic controller description.

\begin{tabular}{|c|c|c|c|c|c|}
\hline Parameter & Units & Default value & Minimum & Maximum & Initial values \\
\hline$F R_{C \_S P}$ & mbar $\min ^{-1}$ & 4 & 0 & 8 & $0^{* *}$ \\
\hline$\% K_{20}$ & $\%$ & 0.65 & 0.5 & 0.8 & 0.6 \\
\hline $\boldsymbol{T M P}_{M A X}$ & bar & 0.45 & 0.3 & 0.6 & $0.3^{* *}$ \\
\hline$S R F_{S P}$ & $\mathrm{~L} \mathrm{~h}^{-1}$ & 2200 & 1700 & 2700 & $2367^{* *}$ \\
\hline$C T$ & $\mathrm{~s}$ & 20 & 10 & 30 & $23.3^{* *}$ \\
\hline FREaN & mbar $\min ^{-1}$ & 0.4 & 0.2 & 0.6 & 0.33 \\
\hline$F R E a P$ & mbar $\min ^{-1}$ & 0.4 & 0.2 & 0.6 & 0.2 \\
\hline FREaZ & mbar $\min ^{-1}$ & 0.4 & 0.2 & 0.6 & 0.2 \\
\hline$F R E c N$ & mbar $\min ^{-1}$ & -1 & -1.5 & -0.5 & -0.5 \\
\hline FREcP & mbar $\min ^{-1}$ & 0 & -0.5 & 0.5 & 1.5 \\
\hline$F R E c Z$ & mbar $\min ^{-1}$ & 1 & 0.5 & 1.5 & 0.17 \\
\hline FRDEAP & mbar $\min ^{-1}$ & 0.9 & 0.45 & 1.35 & 1.35 \\
\hline$F R D E c P$ & mbar $\min ^{-1}$ & 2 & 1 & 3 & 1 \\
\hline FRAEaN & mbar $\min ^{-1}$ & 1.6 & 0.8 & 2.4 & 0.8 \\
\hline$F R A E a P$ & mbar $\min ^{-1}$ & 1.6 & 0.8 & 2.4 & 1.87 \\
\hline FRAEaZ & mbar $\min ^{-1}$ & 1.6 & 0.8 & 2.4 & 1.87 \\
\hline$F R A E c N$ & mbar $\min ^{-1}$ & -4 & -6 & -2 & -6 \\
\hline$F R A E c P$ & mbar $\min ^{-1}$ & 0 & -2 & 2 & $2^{* *}$ \\
\hline$F R A E c Z$ & mbar $\min ^{-1}$ & 4 & 2 & 6 & -2 \\
\hline VBRFsHN & $\mathrm{Nm}^{3} \mathrm{~h}^{-1}$ & -0.4 & -0.6 & -0.2 & -0.33 \\
\hline$V B R F s H P$ & $\mathrm{Nm}^{3} \mathrm{~h}^{-1}$ & -0.16 & -0.24 & 0.08 & $0.2^{* *}$ \\
\hline$V B R F s L N$ & $\mathrm{Nm}^{3} \mathrm{~h}^{-1}$ & 0.16 & 0.08 & 0.24 & -0.08 \\
\hline$V B R F s L P$ & $\mathrm{Nm}^{3} \mathrm{~h}^{-1}$ & 0.4 & 0.2 & 0.6 & 0.13 \\
\hline
\end{tabular}


Table 2. Sensitivity analysis results of fuzzy-logic control parameters: sensitivity measures at different values of $r$. Acronyms for each fuzzy-logic parameter are defined in section 2.2.2.3. Fuzzy-logic controller description.

\begin{tabular}{|c|c|c|c|}
\hline \multicolumn{2}{|l|}{$r=60$} & \multicolumn{2}{|l|}{$r=70$} \\
\hline Parameter & $\mu^{*}$ & Parameter & $\mu^{*}$ \\
\hline FREaP & 0.916 & IBRFsLP & 1.163 \\
\hline IBRFsLP & 0.833 & FREaP & 0.950 \\
\hline IBRFsHP & 0.780 & FREcP & 0.803 \\
\hline AFREcP & 0.776 & $C T$ & 0.724 \\
\hline FREcP & 0.689 & IBRFsHP & 0.717 \\
\hline AFREaN & 0.662 & DFREcP & 0.708 \\
\hline AFREcZ & 0.654 & AFREcP & 0.707 \\
\hline DFREcP & 0.610 & FREaZ & 0.669 \\
\hline DFREaP & 0.596 & AFREcZ & 0.646 \\
\hline$C T$ & 0.549 & AFREaN & 0.636 \\
\hline FREaN & 0.508 & DFREaP & 0.632 \\
\hline IBRFsHN & 0.492 & FREaN & 0.601 \\
\hline AFREaP & 0.479 & FREcN & 0.595 \\
\hline FREcZ & 0.454 & AFREaZ & 0.553 \\
\hline FREaZ & 0.452 & IBRFsHN & 0.507 \\
\hline IBRFsLN & 0.408 & AFREaP & 0.479 \\
\hline AFREaZ & 0.405 & AFREcN & 0.469 \\
\hline FREcN & 0.398 & IBRFsLN & 0.453 \\
\hline AFREcN & 0.390 & FREcZ & 0.437 \\
\hline \multicolumn{2}{|l|}{$r=80$} & \multicolumn{2}{|l|}{$r=90$} \\
\hline Parameter & $\mu^{*}$ & Parameter & $\mu^{*}$ \\
\hline FREaP & 0.846 & $\overline{C T}$ & 0.953 \\
\hline IBRFsLP & 0.843 & IBRFsLP & 0.743 \\
\hline$C T$ & 0.836 & IBRFsHP & 0.739 \\
\hline AFREcP & 0.835 & AFREcP & 0.712 \\
\hline AFREcZ & 0.681 & FREaP & 0.679 \\
\hline IBRFsHP & 0.639 & AFREcZ & 0.646 \\
\hline FREcP & 0.612 & FREcP & 0.623 \\
\hline DFREcP & 0.577 & DFREaP & 0.568 \\
\hline DFREaP & 0.576 & DFREcP & 0.557 \\
\hline FREaZ & 0.570 & FREaZ & 0.526 \\
\hline AFREaN & 0.559 & AFREaZ & 0.504 \\
\hline AFREaZ & 0.519 & AFREaP & 0.487 \\
\hline IBRFSHN & 0.506 & FREaN & 0.485 \\
\hline FREaN & 0.476 & IBRFsLN & 0.484 \\
\hline IBRFsLN & 0.454 & AFREcN & 0.478 \\
\hline AFREaP & 0.426 & FREcZ & 0.458 \\
\hline FREcZ & 0.349 & IBRFSHN & 0.406 \\
\hline$F R E c N$ & 0.345 & AFREaN & 0.350 \\
\hline AFREcN & 0.343 & FREcN & 0.297 \\
\hline
\end{tabular}


Table 3. Sensitivity analysis results of fuzzy-logic control parameters: position factors $\left(P F_{r i} \rightarrow r j\right)$ at different variations in $r$.

\begin{tabular}{ccccccccc}
\hline $\mathrm{r}_{\mathrm{i}} \rightarrow \mathrm{r}_{\mathrm{j}}$ & $10 \rightarrow 20$ & $20 \rightarrow 30$ & $30 \rightarrow 40$ & $40 \rightarrow 50$ & $50 \rightarrow 60$ & $60 \rightarrow 70$ & $70 \rightarrow 80$ & $80 \rightarrow 90$ \\
\hline $\mathrm{PF}_{\mathrm{ri} \rightarrow \mathrm{rj}}$ & 0.84 & 0.74 & 0.76 & 0.72 & 0.78 & 0.37 & 0.29 & 0.26 \\
\hline
\end{tabular}


Table 4. Sensitivity analysis results of advanced controller set points: sensitivity measures at different values of $r$.

\begin{tabular}{|c|c|c|c|}
\hline \multicolumn{2}{|l|}{$r=20$} & \multicolumn{2}{|l|}{$r=30$} \\
\hline Parameter & $\boldsymbol{\mu} *$ & Parameter & $\mu^{*}$ \\
\hline$F R_{C_{-} S P}$ & 2.556 & $F R_{C_{-} S P}$ & 2.602 \\
\hline$\% K_{20}$ & 0.239 & $T M P_{M A X}$ & 0.276 \\
\hline TMP $_{M A X}$ & 0.215 & $S R F_{S P}$ & 0.186 \\
\hline$S R F_{S P}$ & 0.191 & $\% K_{20}$ & 0.142 \\
\hline \multicolumn{2}{|l|}{$r=40$} & \multicolumn{2}{|l|}{$r=50$} \\
\hline Parameter & $\boldsymbol{\mu}^{*}$ & Parameter & $\boldsymbol{\mu} *$ \\
\hline$F R_{C \_} S P$ & 2.650 & $F R_{C_{-} S P}$ & 2.630 \\
\hline$S R F_{S P}$ & 0.217 & $T M P_{M A X}$ & 0.216 \\
\hline$T M P_{M A X}$ & 0.213 & $S R F_{S P}$ & 0.215 \\
\hline$\% K_{20}$ & 0.188 & $\% K_{20}$ & 0.161 \\
\hline
\end{tabular}


Table 5. Sensitivity analysis results of advanced controller set points: position factors $\left(P F_{r i} \rightarrow r j\right)$ at different variations in $r$.

\begin{tabular}{ccccc}
\hline $\mathrm{r}_{\mathrm{i}} \rightarrow \mathrm{r}_{\mathrm{j}}$ & $10 \rightarrow 20$ & $20 \rightarrow 30$ & $30 \rightarrow 40$ & $40 \rightarrow 50$ \\
\hline $\mathrm{PF}_{\mathrm{ri} \rightarrow \mathrm{rj}}$ & 0.00 & 0.41 & 0.24 & 0.24 \\
\hline
\end{tabular}




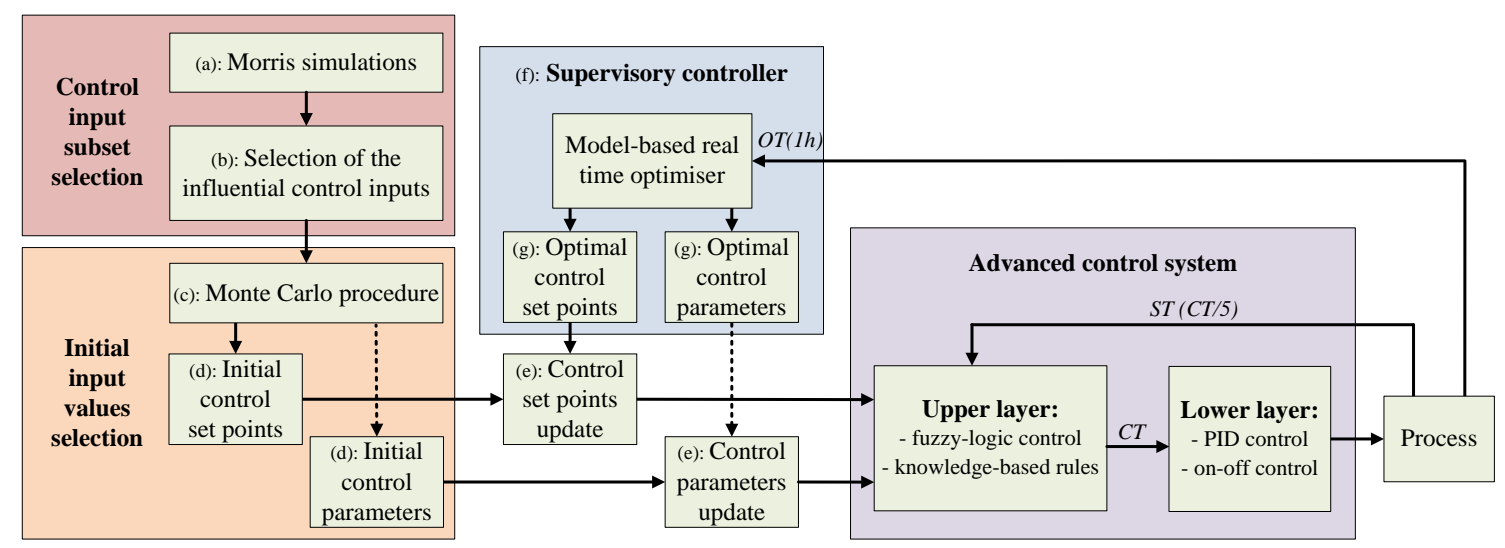

(a)

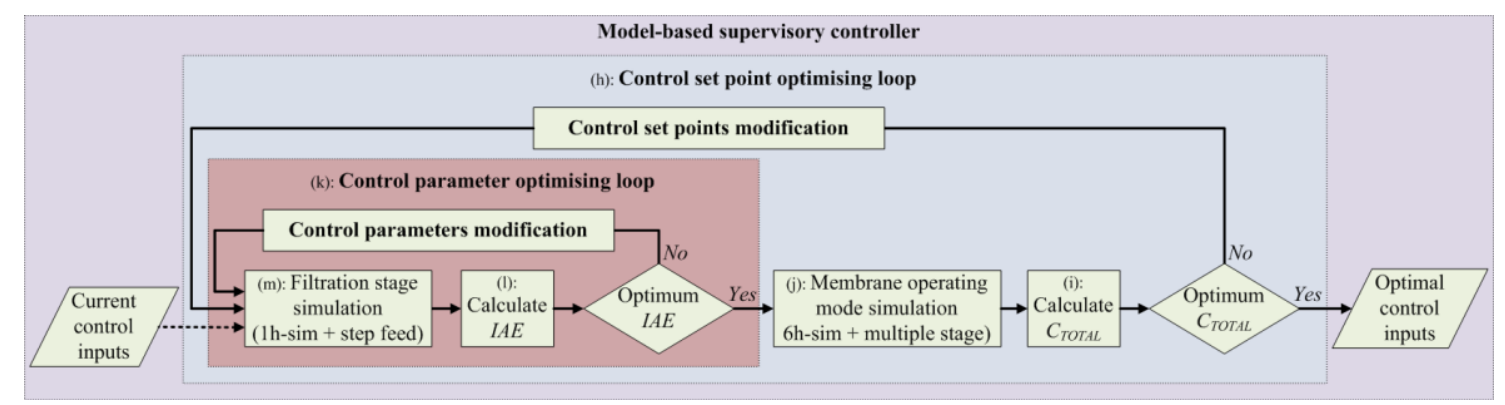

(b)

Figure 1. (a) Flow chart of proposed methodology for real-time optimisation of filtration in submerged

AnMBRs. (b) Flow chart of model-based supervisory controller. 


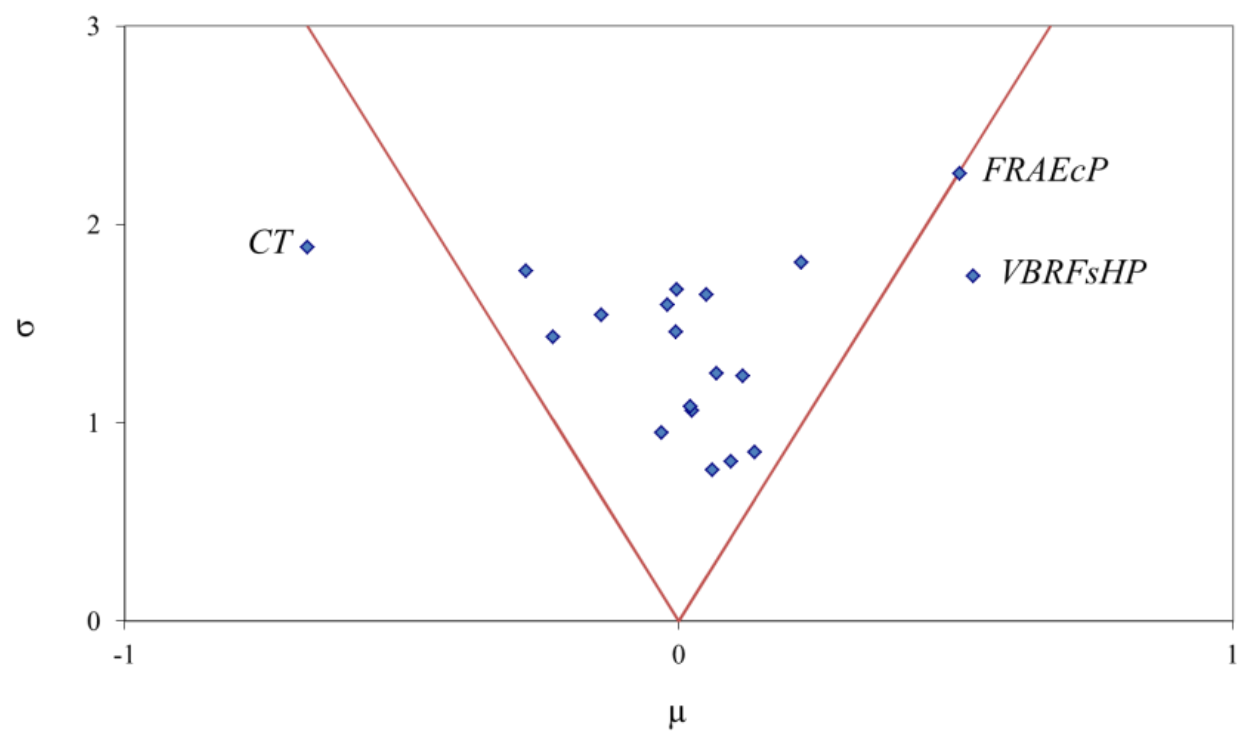

(a)

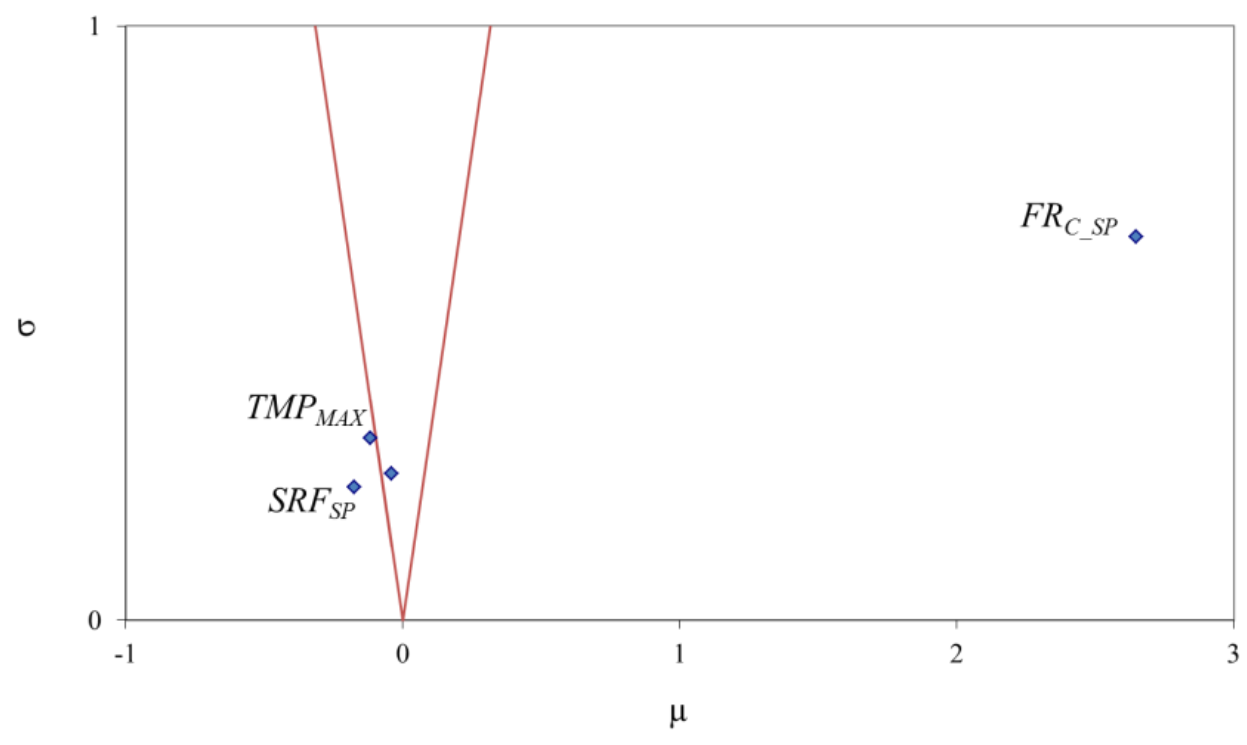

(b)

Figure 2. Sensitivity analysis results of: (a) fuzzy-logic control parameters ( $\mu$ versus $\sigma$ when final value of $r=80$ ); and (b) advanced controller set points ( $\mu$ versus $\sigma$ when final value of $r=40$ ). Lines plotted according to $\mu_{i}= \pm 2 S E M_{i}$. 


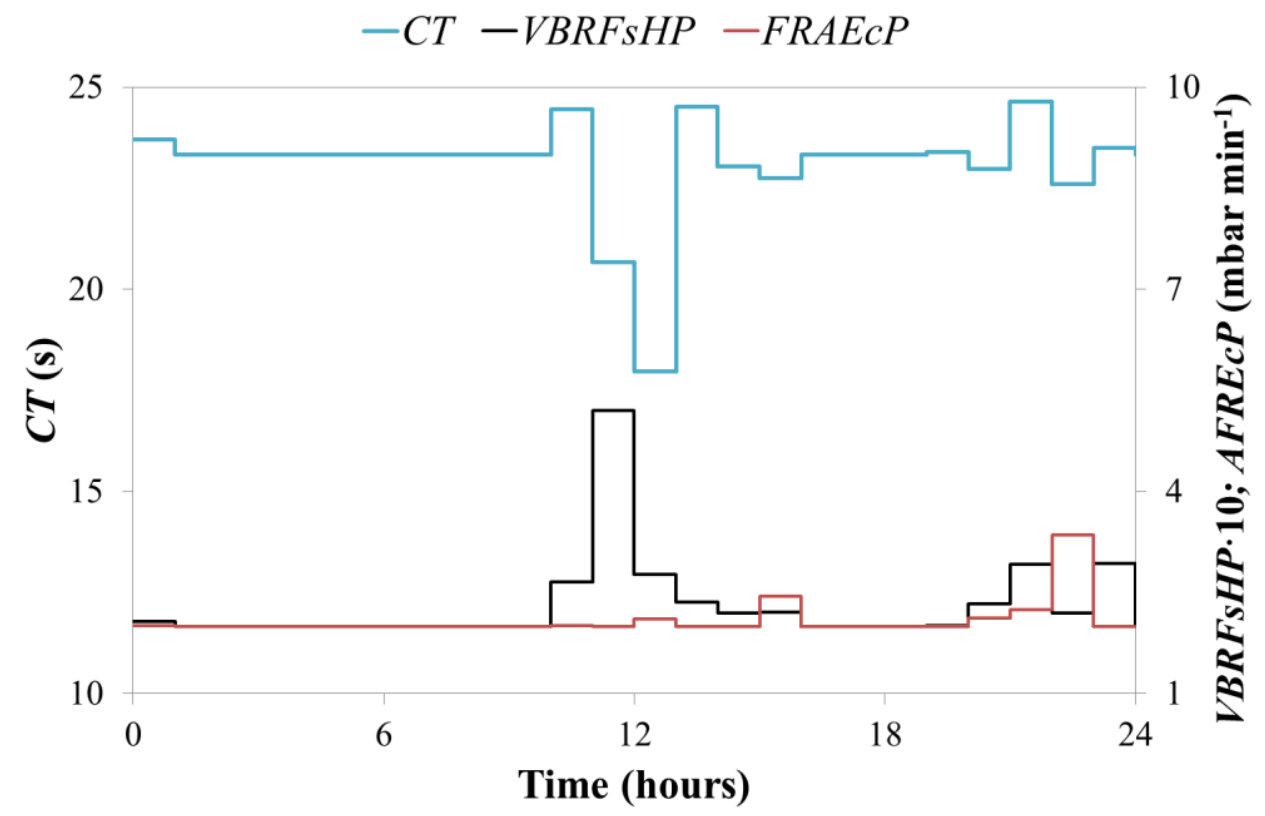

Figure 3. Evolution of optimised values of fuzzy-logic control parameters identified as highly-influential using the Morris screening method. 


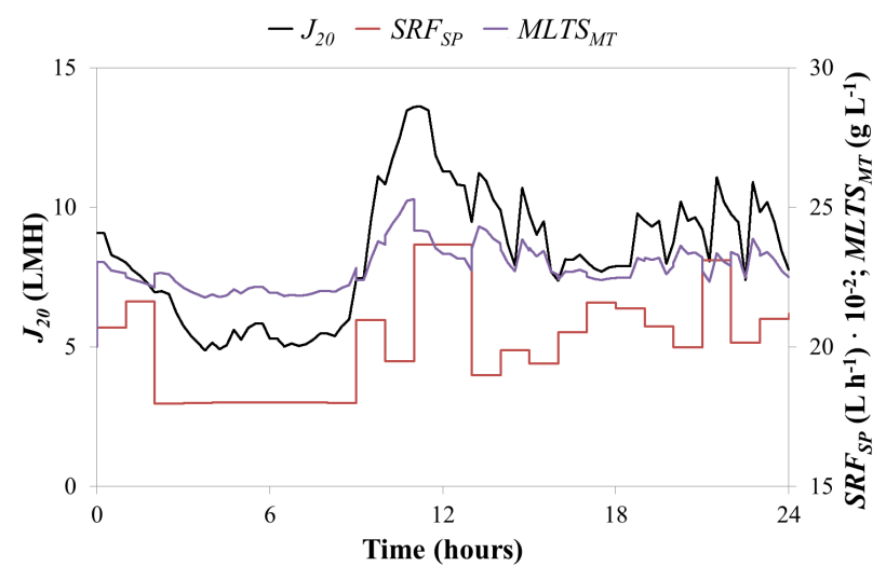

(a)

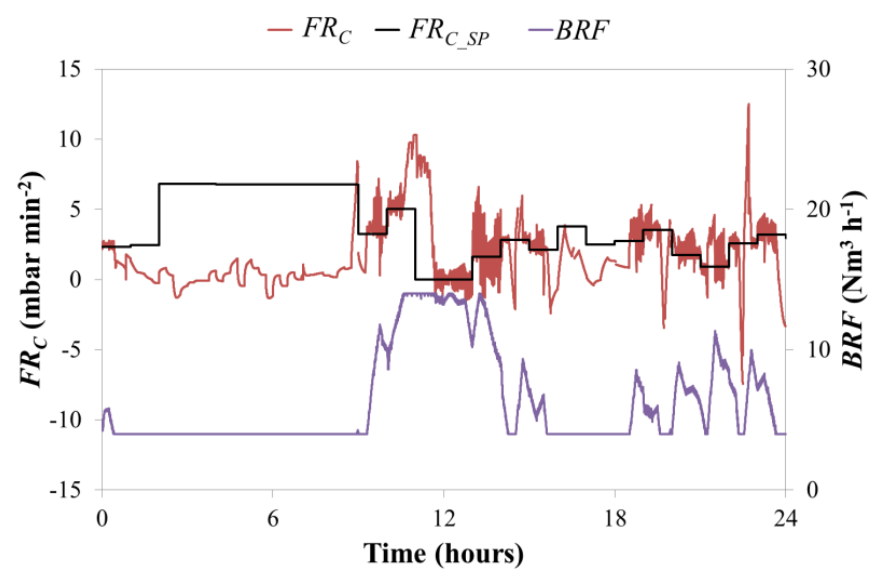

(b)

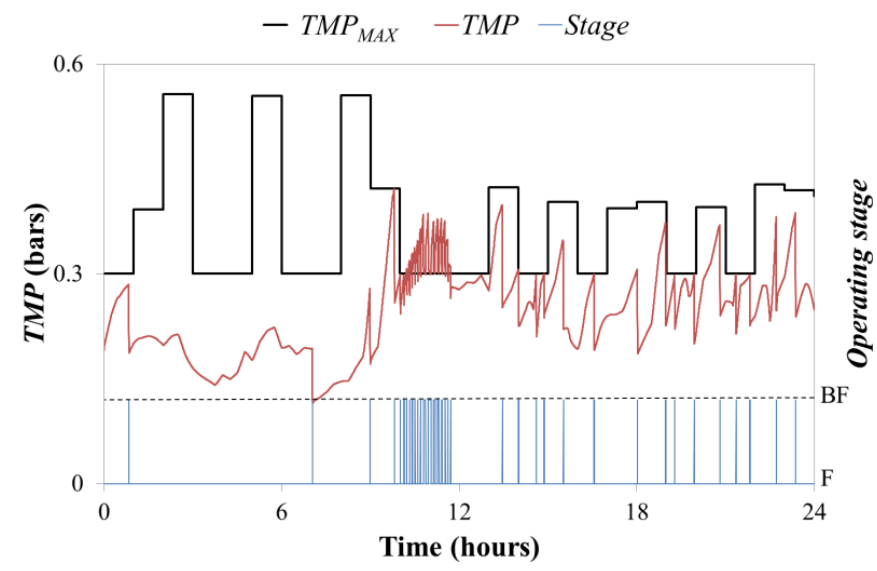

(c)

Figure 4. Optimised values of advanced controller set points identified as highly-influential using the Morris screening method and modelled results of main operating variables when the model-based supervisory controller was running. Evolution of: (a) $\mathrm{SRF}_{\mathrm{SP}}$, MLTS $\mathrm{MT}_{\mathrm{MT}}$ and $\mathrm{J}_{20}$; (b) FR__SP, FR $\mathrm{FR}_{\mathrm{C}}$ and BRF; and (c) TMP $\mathrm{TAX}_{\mathrm{MAX}}$ TMP and membrane operating stage. 


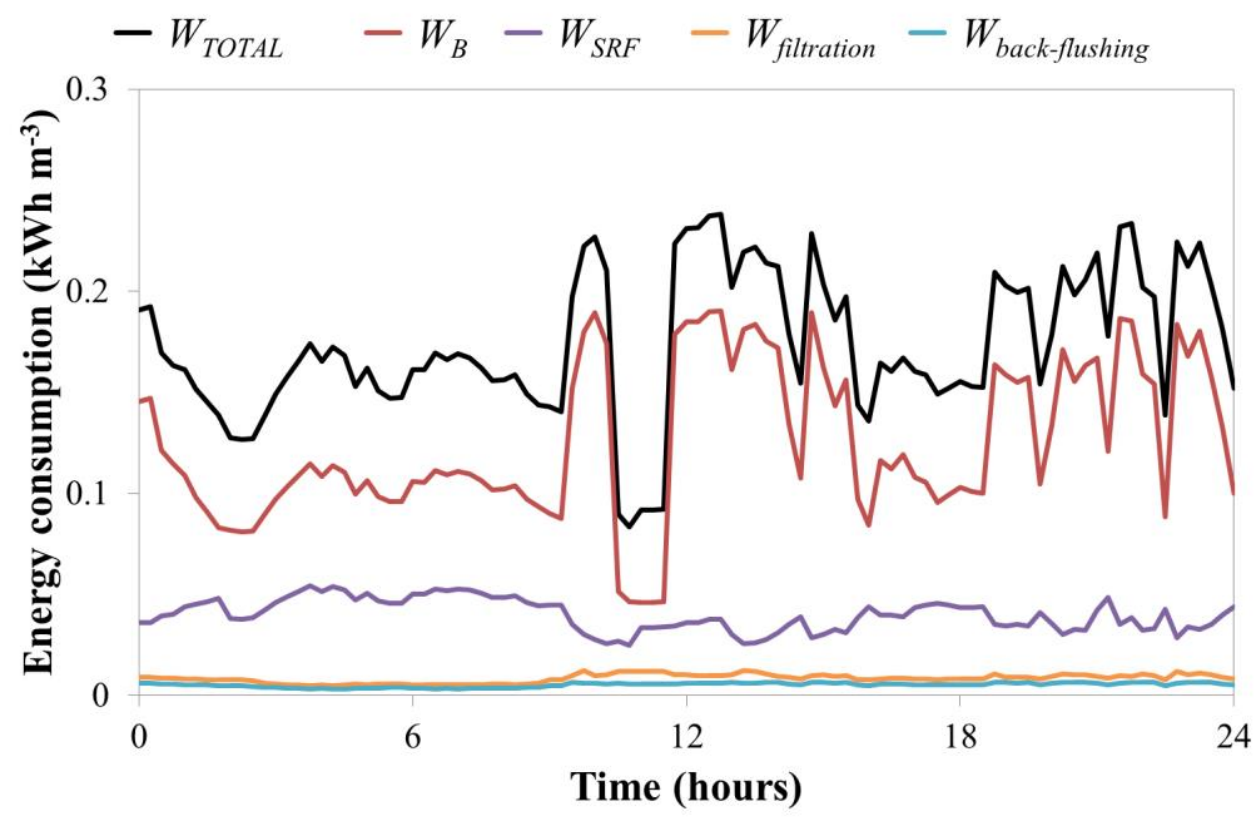

(a)

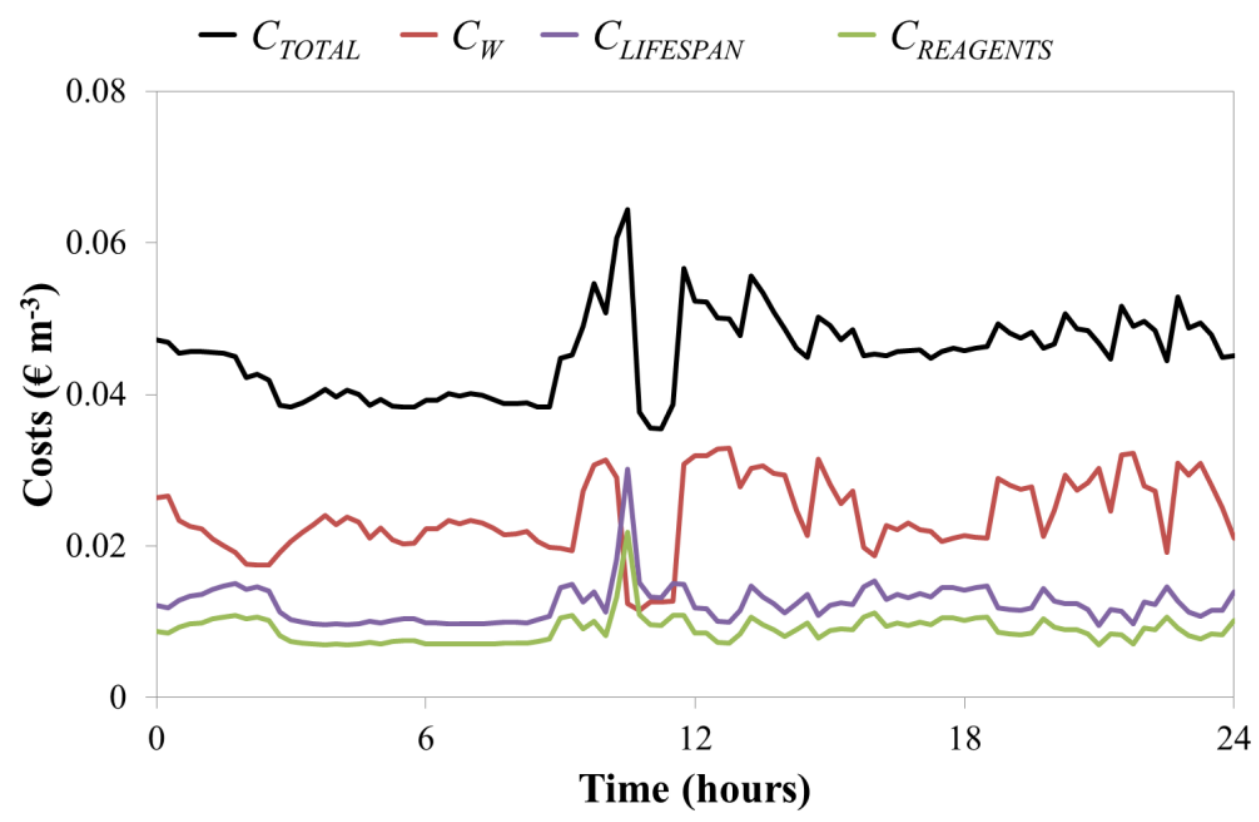

(b)

Figure 5. Model-based supervisory control performance. Evolution of: (a) $W_{T O T A L}, W_{B}, W_{S R F}, W_{\text {filtration }}$ and $W_{\text {back-flushing; }}$ and (b) $C_{T O T A L}, C_{W}, C_{R E A G E N T S}$ and $C_{\text {LIFESPAN. }}$ 
